\title{
LOS MÁRGENES URBANOS COMO ARTICULADORES DE LA CIUDAD Y SU ENTORNO: LINEAMIENTOS ESTRATÉGICOS PARA EL DESARROLLO SOSTENIBLE DEL MARGEN OCCIDENTAL DE BUCARAMANGA \\ Deisy Katherine Peña Jaimes - Lina María Ortega Torres*
}

Imagen A. Fotografía del reconocimiento del Margen Occidental de Bucaramanga, interacción conflictiva de la industria, la Quebrada Chimitá y los asentamientos humanos .Fuente: Autoras del Proyecto.

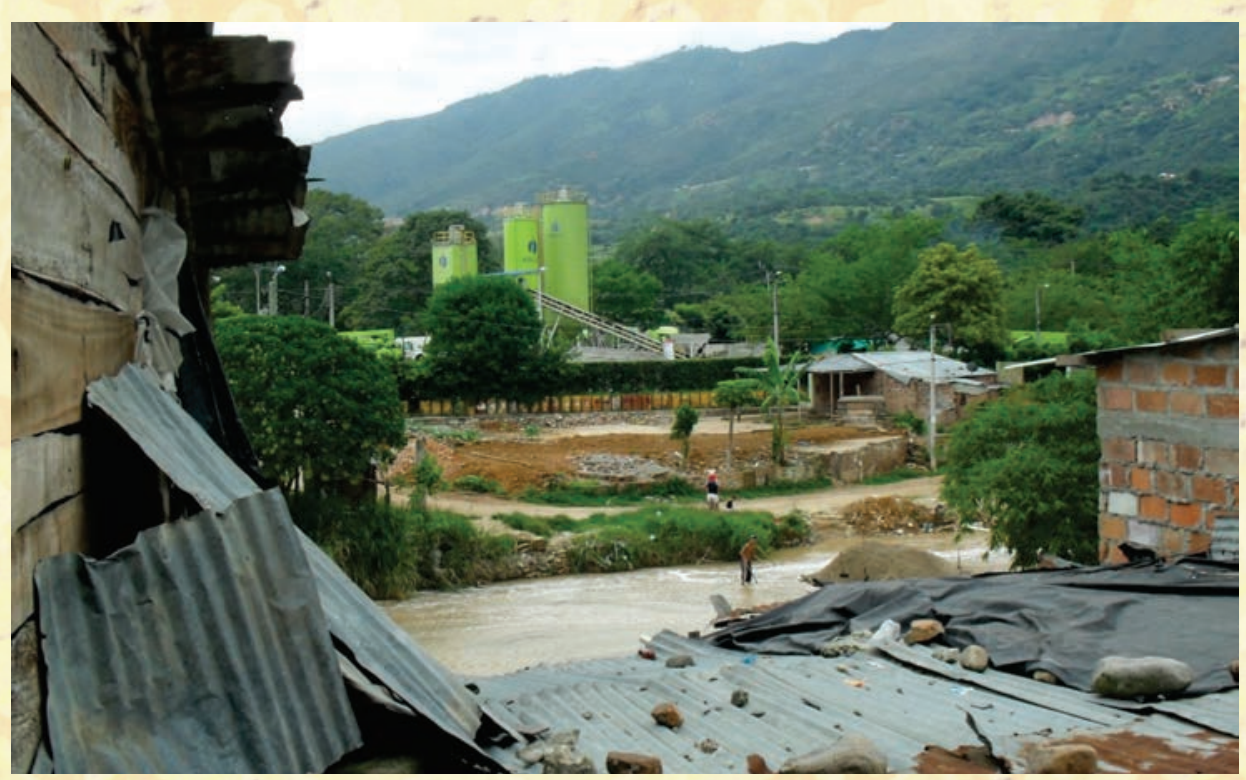

\section{RESUMEN}

Después de la década del 30, el desarrollo de Bucaramanga estuvo acompañado por una serie de procesos y problemáticas inherentes al fenómeno de la expansión urbana, la cual incidió directamente sobre los márgenes de la ciudad, territorio irresoluto que aún afronta constantes mutaciones y envuelve eventualidades y circunstancias específicas. A pesar de ello, el municipio de Bucaramanga no registra intervenciones urbanas en sus escenarios de margen, situación que lleva a poner, una vez más, sobre la mesa los beneficios potenciales que una oportuna planeación territorial conferiría a sus márgenes urbanos. En consecuencia, la presente investigación se propone como una herramienta útil desde un punto de vista práctico y otro metodológico. El primero busca reconocer las condiciones actuales de las franjas periféricas de la ciudad a fin de identificar cuál de los márgenes genera actualmente el mayor impacto negativo sobre el territorio, con el objetivo de formular los lineamientos de crecimiento sostenible para intervenir el margen y al mismo tiempo usarlo como herramienta de planeación urbana. Desde el punto de vista metodológico, la investigación propone una técnica de análisis para abordar minuciosamente la problemática del margen urbano más afectado, estructurada en cuatro capítulos que se articulan en torno a un hilo conductor generado por un análisis secuencial que va desde la identificación de las condiciones existentes en los márgenes de la ciudad, su análisis y el diagnóstico, para después proseguir con una retroalimentación que conducirá a abordar los problemas específicos del margen seleccionado y formular una serie de lineamientos que se materializarán en intervenciones y acciones dirigidas a proteger, potenciar y valorar uno de los múltiples escenarios periurbanos de Bucaramanga.

\section{PALABRAS CLAVE}

Márgenes Urbanos, Planeación Urbana, Lineamientos, Crecimiento Sostenible, Bucaramanga. 


\section{URBAN MARGINS AS ARTICULATORS OF THE CITY AND ITS ENVIRONMENT: STRATEGIC GUIDELINES FOR THE SUSTAINABLE DEVELOPMENT OF WESTERN MARGIN OF BUCARAMANGA}

Deisy Katherine Peña Jaimes - Lina María Ortega Torres

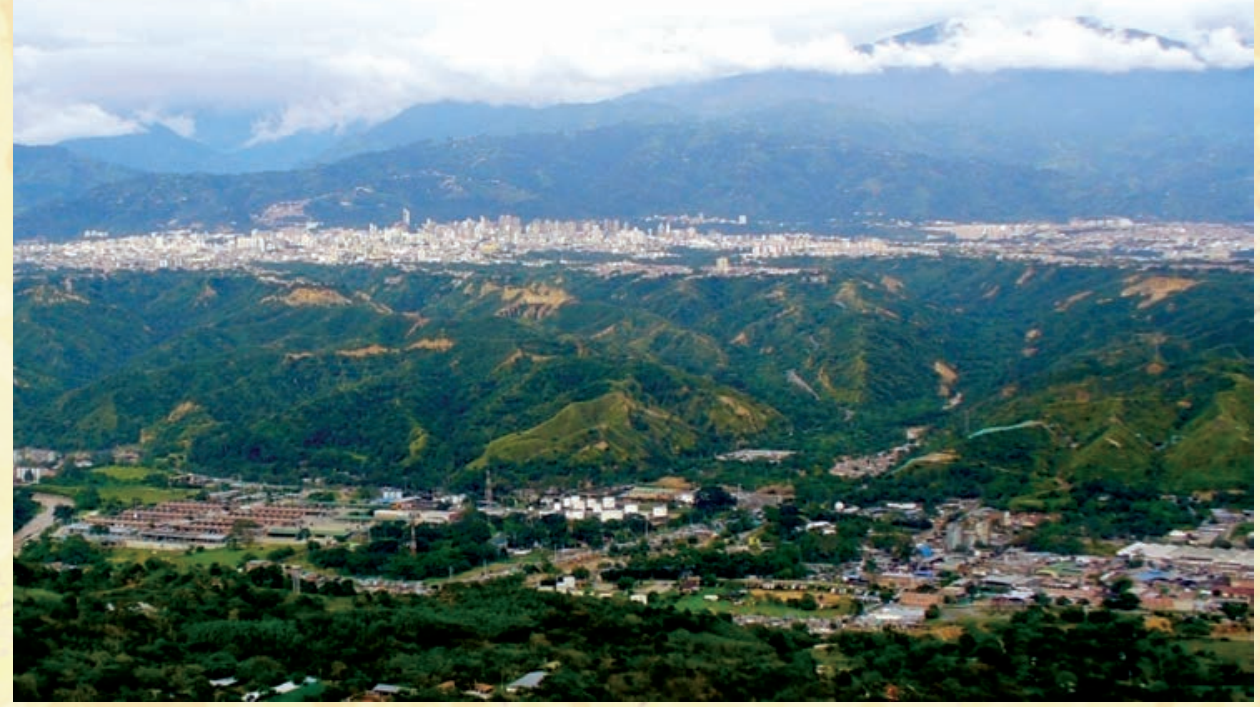

\section{ABSTRACT}

After the decade of 30, Bucaramanga's development has been accompanied by a series of processes and problems related to the phenomenon of urban sprawl which has a direct impact on the margins of the city: unresolved territory that is still facing constant mutations and involving contingencies and specific circumstances. Despite a common awareness of this situation, the municipality of Bucaramanga not register interventions on their urban outskirts, a situation that leads to put on the agenda again the potential benefits that a timely land planning would give to urban margins. Consequently, this research is proposed as a useful tool focuses on practical and methodological issues. The first one seeks to recognize the current conditions of the outer fringes of the city in order to identify which one currently generates the largest negative impact on the territory, pointing to formulate guidelines for a sustainable land intervention and also using the margin as a tool for urban planning. From the methodological point of view, this research proposes an analysis technique to address thoroughly the problem of most affected urban fringe, divided into four chapters that are organized around a sequential analysis ranging from the identification of conditions in the margins of the city, their analysis and diagnosis, and then proceed with a feedback that will take to deal with specific problems of selected range and make a series of guidelines that will materialize on interventions and actions to protect, enhance and valorize one of the many peri-urban settings of Bucaramanga.

\section{KEY WORDS:}

Urban Margin, Urban Planning, Guidelines, Sustainable Development, Bucaramanga.
* Este artículo es producto de la investigación realizada para optar por el título de arquitectas en la Facultad de Arquitectura de la Universidad Santo Tomás, seccional Bucaramanga, la cual fue Laureada.

* El proyecto fue dirigido por el arquitecto Jorge Alberto Villamizar Hernández y co-director el arquitecto Carlos Humberto Gómez Arciniegas.
Imagen B. Fotografía de reconocimiento del Margen Occidental de Bucaramanga, panorámica, arriba abanico aluvial de Bucaramanga, abajo valle del Río de Oro. Fuente: Autoras del Proyecto. 


\section{INTRODUCCIÓN}

La planeación urbana es la herramienta que permite coordinar el desarrollo o creación de las ciudades, acorde a las condiciones existentes en el territorio, su sistema social (actual y futuro), el necesario equilibrio entre éstos y las actividades, usos y equipamientos allí presentes. Refleja además, el deseo de los hombres por organizar su espacio en función de diferentes proyectos específicos, sostenibles y estructurantes del desarrollo urbano de la ciudad y de las diferentes eventualidades que implica. Los efectos deseados se revertirían en una estructuración del crecimiento sostenible de la ciudad que impida crecimientos incontrolados, desordenados y desarticulados funcionalmente de la estructura urbana, causa de una saturación del territorio con problemáticas de orden económico, político, social, cultural, ambiental e incluso geomorfológico y climático. Entran aquí en escena los márgenes urbanos que se pueden definir como escenarios de borde en los que la estructura urbana se articula con los componentes rurales y ambientales del entorno, dotados de una característica peculiar por ser espacios donde los influjos urbanos son más pronunciados a causa de la misma inmediatez física a la ciudad que genera sinergias únicas al compaginarse procesos económicos, demográficos, sociales y territoriales que detonan en una mezcla de usos del suelo generalmente incompatibles y que inciden negativamente en el medio ambiente. Ante estas consideraciones es imposible absolver el municipio de Bucaramanga en términos de una acertada planificación de planeación de los márgenes urbanos, laguna que ha tolerado la degradación de ecosistemas vitales para el sostenimiento ambiental de la ciudad; la conurbación desordenada con los municipios vecinos que altera drásticamente la estructura urbana de éstos; un sprawl urbano' innecesario que aumenta los tiempos de traslado y obliga a recorrer mayores distancias en automóvil con la consiguiente carga de contaminación por dióxido de carbono en el aire; la proliferación de asentamientos informales en precarias condiciones a causa de la inexistencia de políticas acertadas para la construcción de vivienda digna y que genera tensiones sociales por las demandas insatisfechas de equipamientos e infraestructura y el cambio acelerado de uso de suelo rural por áreas de expansión urbana que resultan en la parcelación indiscriminada e individualista de ese territorio, pues ignoran o relegan a un segundo plano espacios vitales para implantar equipamientos comunitarios, escenarios de encuentro, áreas verdes o adecuados perfiles viales. Por otra parte, Bucaramanga es un municipio limitado topográficamente en sus márgenes Norte, Nororiental y Oriental, con una tensionante situación de conurbación física por el margen Sur con el municipio de Floridablanca y con la necesidad de la planeación del futuro crecimiento en el Margen Occidental, uno de los pocos espacios que tiene la ciudad para proyectar su crecimiento físico y el escenario que actualmente genera el mayor impacto negativo en el territorio por su alto índice de contaminación y por ser "escenario de olvido", perfecto para la ubicación de asentamientos informales. A la luz de estas consideraciones, nace el problema de la presente investigación, fundamentada en la falta de planeación de los márgenes urbanos y en una serie de cuestionamientos que se han formulando para abordar la investigación: ¿Las tendencias y los factores del crecimiento histórico de la ciudad han incidido en las condiciones actuales de los márgenes urbanos?; ¿Son los márgenes urbanos los espacios encargados de articular el crecimiento de la ciudad con su entorno?; iSe han realizado intervenciones urbanas bajo el contexto periurbano que estructuren el crecimiento sostenible de la ciudad?; ¿El ordenamiento físico de las actividades y recursos de los márgenes urbanos, basados en las características socio-económicas y ambientales del territorio, permite la potencialización y el crecimiento sostenible del territorio periurbano?

Para individuar la posible respuesta a estos planteamientos, se organiza entonces el presente documento en 4 capítulos que buscan estudiar la situación actual de los márgenes urbanos

I INGERSOLL, Richard. Sprawltown. Roma, Meltemi editore, 2004 
de Bucaramanga, intención que se fundamenta en una preocupación por el destino de este tercer territorio y en estudios y pronunciaciones realizados hasta el momento en Europa como la Convención Europea del Paisaje, la cual resalta el rol fundamental de los márgenes urbanos en la planificación del paisaje, explícitamente aplicable sobre todo a las "zonas más afectadas por el cambio y fuertemente deterioradas (periferias, zonas periurbanas zonas e industriales y zonas costeras)" ${ }^{2}$

El Capítulo I se estructura a partir del análisis del crecimiento histórico de Bucaramanga y los escenarios que en ella se han generado, con particular atención a las áreas de margen que a través de la historia han absorbido el crecimiento urbano y generado dinámicas específicas en nuestro contexto. Esta investigación se apoya además en un estudio sobre los conceptos básicos de la planificación territorial, reflejados en la bibliografía presentada al final del artículo, que sirvieron como hilo conductor del desarrollo de la investigación.

En el capítulo 2 se toma como punto de partida el análisis de las condiciones actuales de los márgenes en Bucaramanga, resultado del crecimiento urbano analizado en el primer capítulo, con el fin de identificar las problemáticas generales desde una aproximación general, para después pasar a un enfoque más especifico y emitir un diagnóstico sobre el margen que mayor impacto negativo genera en el territorio.

Antes de pronunciar cualquier lineamiento de planificación o propuesta proyectual, el capítulo 3 analiza una serie de estudios de caso (referentes) que resaltan el modo en el cual los márgenes urbanos han sido asumidos en otros contextos como candidatos a convertirse en lugares privilegiados para su crecimiento y transformación interna, para la recuperación de las áreas industriales deterioradas o abandonadas, para el mejoramiento de las condiciones de vida y del aumento del bienestar mediante una mayor utilización de los servicios y el mejoramiento de la fisonomía de la ciudad.

Una vez individuados los elementos que pueden ser retomados o reevaluados para el margen objeto de la intervención, el capítulo 4 entra en la dimensión del ordenamiento del territorio, escenario de diseño, una reflexión inevitablemente local que no puede separarse de una concepción general, fundamentada en los elementos reguladores identificados en las condiciones actuales del Margen Occidental y que darán origen a lineamientos estratégicos para su crecimiento sostenible, con la esperanza de que esta investigación dé pie a posteriores estudios sobre éste $u$ otros márgenes urbanos de Bucaramanga y/o de otros centros urbanos del país.

\section{LOS MÁRGENES URBANOS EN LA INVESTIGACIÓN: DESDE SU ASUNCIÓN COMO ARTICULADORES DEL TERRITORIO HASTA SU POTENCIAL COMO ESCENARIOS PARA SU DESARROLLO}

“El margen, por su naturaleza, no tiene una morfología reconocible. Es lo opuesto a la frontera. Mientras que la frontera es neta el margen es irregular. Mientras que la frontera encierra, el margen permanece abierto. Donde la frontera es intransitable y marca un interior y un exterior, el margen entra, sale y se puede atravesar. Donde la frontera está dibujada, reconocida y, a menudo, representada por una

2 Palazzo, Danilo. Responsabilità progettuali e paesaggio dei margine urbani. en Ri-viste per la progettazione del paesaggio, año 4, No. 6, Florencia, UNIFI, 2006 
construcción o un elemento, el margen se sitúa al azar, es indistinguible y carente de elemento que físicamente le dé sustancia"3

Estas premisas sirven como fundamento del presente trabajo en el cual se plantea como objetivo general, estudiar la situación de los márgenes urbanos de Bucaramanga habida cuenta que el margen actúa como espacio articulador y estructurante del crecimiento de la ciudad, apuesta a formular una serie de lineamientos estratégicos para el crecimiento sostenible en el Margen Occidental (Eje ambiental del Río de Oro) que revertirá en la potencialización del territorio inmediato y la articulación armónica de las actividades en relación con el sistema ambiental. Este objetivo determina, por lo tanto, la definición de unos objetivos específicos que aportarán en el proceso de identificar los márgenes existentes en Bucaramanga, a través de una investigación que toma como principal punto de partida el examen del crecimiento histórico del Municipio de Bucaramanga, en el ámbito social y territorial.

El proceso lleva a formular otro objetivo específico que conlleva a estudiar la situación de los márgenes urbanos de Bucaramanga para identificar los aspectos ambientales, físicos y las dinámicas socioeconómicas desarrolladas en este tipo de espacios periurbanos, a fin de escoger uno de los márgenes que tras una intervención urbana potencialice y estructure el crecimiento sostenible de su entorno. Este propósito requiere un soporte que implica referenciar intervenciones urbanas formuladas bajo el contexto periurbano que contengan similitudes con las oportunidades, problemáticas o debilidades diagnosticadas en el sitio que se va a intervenir, con la intensión de obtener conclusiones acertadas para la formulación de la propuesta urbana.

El proceso investigativo culmina entonces con el cumplimiento del último objetivo específico que propende por estructurar un ordenamiento físico de las diferentes actividades y recursos del margen seleccionado, de acuerdo a las características socio-económicas y respetando las condiciones ecológicas del entorno mediante la formulación de los lineamientos estratégicos de crecimiento sostenible. Para el mejor alcance de los objetivos planteados en la investigación, se realiza una clasificación por su condición territorial, lo que genera 5 áreas de reconocimiento: Margen Norte, Margen Nororiental, Margen Oriental, Margen Sur y Margen Occidental.

\section{LOS PRINCIPALES CONCEPTOS BÁSICOS DE LA PLANIFICACIÓN DEL TERRITORIO COMO REGULADORES DE LA INVESTIGACIÓN}

Una vez establecidos los objetivos de la investigación, se escudriñó aún más en el campo de la planificación territorial para definir un escenario donde se pudiesen aplicar una serie de principios de acción sobre éste, previstos en un modo dinámico y con proyección, a saber salvaguarda, gestión y, de hecho, planificación. Esta última, conduce el proceso hacia un manejo proyectual que involucra diferentes situaciones espaciales:

- Áreas Peri-urbanas: Encuentro de lo urbano con lo rural o con los sistemas ecológicos. El ambiente habitable entre las áreas urbanas y rurales, es un conjunto fragmentado de usos del suelo urbano (habitación para ricos y pobres, así como industria) usos naturales como lagos y bosques y usos rurales como fincas, pesca y minería; así como es un área diversa, que ofrece acceso a trabajos tanto urbanos

3 M. C TREU, D. Palazzo. Margini. Descrizioni, strategie. Italia, Progetti, 2006 
como rurales, con diferentes instituciones, tipos de costumbres, leyes y prácticas que afectan las decisiones $y$ acciones que se toman en ella ${ }^{4}$

En palabras de Manuel Castells, se incluyen, en discontinuidad espacial, zonas construidas de diversa densidad, espacios abiertos, actividades agrícolas, reservas naturales, extensiones residenciales y concentraciones de servicios y actividades industriales, repartidos a lo largo de ejes de transporte constituidos por autopistas y sistemas de transporte público. No existe una verdadera división en zonas, ya que los lugares de trabajo y las áreas residenciales y comerciales están dispersas en varias direcciones. Es más, aunque estas regiones suelen estar centradas en torno a una gran ciudad central, los centros urbanos menores quedan gradualmente absorbidos en redes intrametropolitanas ${ }^{5}$

- Borde: Límite a lo construido urbano, consolidación de lo suburbano y área de enlace de las relaciones regionales ${ }^{6}$

- Conurbación: o aproximación física progresiva de la ciudad principal y uno o varios de los centros vecinos, o-el conjunto de estos- como resultado de una dinámica de crecimiento acelerado e incontrolado y periférico ${ }^{7}$

- Elementos de Estructura: sistemas físicos que expresan relaciones estables entre componentes seleccionados de ese territorio, es decir, los elementos que ligan un número reducido de partes ${ }^{8}$

- Enclaves Singulares: articulan la estructura general del territorio y no son sólo por su singularidad dentro de cada unidad de paisaje, dependen de la función que se analicen ${ }^{9}$

- Franja Peri-urbana: es un espacio de transición que - por el momento - no es ni rural ni urbano pero en el que coexisten ambos en razón de su plurifuncionalidad ${ }^{10}$. Se trata de un espacio intermedio y sin delimitación aparente de lo que es considerado campo y lo que tratamos de definir como ciudad. La mezcolanza de estos dos espacios, así como de los usos del suelo y del tipo de organización social, viene dada a través de la dialéctica campo"

- Margen: aquella franja territorial que denota una transición de los aspectos urbanos predominantes: densidad de ocupación, morfología, usos urbanos y dinámicas socioculturales, entre otros, a lo natural, o hacia los usos de suelos rural ${ }^{12}$

- Periferia: aquella franja territorial que denota una transición de los aspectos urbanos predominantes: densidad de ocupación, morfología, usos urbanos y dinámicas socioculturales, entre otros, a lo natural, o hacia los usos de suelos rurales ${ }^{13}$

- Periferia Urbana: áreas que bordean la ciudad, que se sitúan en sus límites, marcan la transición entre el espacio urbano y el rural. ${ }^{14}$

4 TORO VASCO, Carolina; VELASCO BERNAL, Vanessa; NIÑO SOTO, Alexánder. El borde como espacio articulador de la Ciudad Actual y su Entorno. Revista de Ingenierías Universidad de Medellín, Julio-Diciembre, Año/Vol 4, No. 007. Medellín, 2005 p. 58

5 ENTRENA DURÁN, Francisco. Procesos de Peri urbanización y cambios en los modelos de ciudad. Un estudio europeo de casos sobre sus causas y consecuencias. Papers 78. Universidad de Granada, Departamento de Sociología, España, 2005 Pp. 59-88

6 TORO VASCO, Carolina; VELASCO BERNAL, Vanessa; NIÑO SOTO, Alexánder. Op. Cit.

7 CASTELLS, Manuel. Imperialismo y América Latina. Barcelona, Gustavo Gill, 1973

8 GIMÉNEZ BALDRÉS, Enrique J. Parcelaciones Residenciales Subnormales. Valencia, Universidad Politécnica de Valencia, 2010

9 Ibíd

10 SARASA, José Andrés. Las Áreas periurbanas: Espacios plurifuncionales en crisis. IX Coloquio de Geógrafos Españoles. Murcia, Centro Editorial de Servicios y Publicaciones Universitarias, 1985

II MIKEL, Razkin Fraile. De la potencialidad a la realidad en la franja periurbana del norte de Pampl ona- Ureña.

12 TORO VASCO, Carolina; VELASCO BERNAL, Vanessa; NIÑO SOTO, Alexánder. Op. Cit

13 lbíd

14 FERIA TORIBIO, José María. Nuevas periferias urbanas y planificación pública. En DOMÍNGUEZ, R. (coord.): La ciudad. Tamaño y crecimiento, pp. 309-3 I. Málaga, Departamento de Geografía de la Universidad de Málaga y AGE, 1999 
- Primera Periferia: es un espacio de soporte pasivo de cuanto el centro rechaza o no puede contener, generalmente son espacios sin calidad, con valores urbanos y ambientales, inferiores a los dos escenarios de contacto. Caracterizados por una dualidad identitaria histórica, carentes de una estructura edificada ${ }^{15}$

- Segunda Periferia: está configurada por la ciudad difusa, reticular y distante de los centros principales. Es una ciudad sin centro interconexión, de sistemas urbanos autónomos, complementarios e interdependientes ${ }^{16}$

- Suelo: bien sea urbano, rural, de expansión o de protección, visto en términos de mercado, para lo cual la gestión urbanística busca interpretar e intervenir en el comportamiento, oferta y demanda, en el contexto de su consideración como un recurso escaso y, a su vez, en su condición de insumo en la construcción del espacio urbano y la provisión de bienes públicos por parte del Estado ${ }^{17}$

- Territorio: principalmente el espacio urbano, el cual es el objeto de los procesos de planificación, mediante los cuales el pacto colectivo se expresa a través de la aplicación del principio de la función pública del urbanismo, en determinaciones de carácter administrativo. ${ }^{18}$

- Unidades de Paisaje: unidad estructural apoyada en las caracteristicas topográficas y en la lectura de los límites visuales, donde existen una apreciable homogeneidad en el resto de los elementos que comoponen la forma del territorio. ${ }^{19}$

\section{LA APREHENSIÓN DE LOS MÁRGENES URBANOS DE BUCARAMANGA A TRAVÉS DE LA METODOLOGÍA DE LA INVESTIGACIÓN}

La propuesta metodológica según la cual se estructura el presente trabajo se fundamenta en el método científico pues es una investigación de tipo aplicada por su carácter práctico. La investigación es una actividad encaminada a la solución de problemas, su objetivo consiste en hallar respuestas a preguntas, mediante el empleo de métodos y técnicas; los métodos son técnicas lo suficientemente generales para convertirse en procedimientos comunes y las técnicas son los medios o herramientas para ejecutar los procedimientos propuestos en la investigación.

"Investigar es el proceso que, utilizando el método científico, permite obtener nuevos conocimientos en el campo de la realidad social o bien estudiar una situación para diagnosticar necesidades y problemas a efectos de aplicar los conocimientos con fines prácticos". ${ }^{20}$

El proceso investigativo nace con la formulación de un problema y la propuesta de preguntas que orienten la investigación; no se debe olvidar que la elección del tema a investigar quizá se constituya como el evento más trascendental de la investigación pues de él depende el rumbo y la viabilidad de las metas. El problema abordado en el presente trabajo se fundamenta en la falta de planeación y ordenamiento de los márgenes urbanos de la ciudad de

15 TORO VASCO, Carolina; VELASCO BERNAL, Vanessa; NIÑO SO TO, Alexander. Op. Cit.

16 Ibíd

17 FRANCO, Ángela María. Desarrollos prácticos en Ordenamiento Territorial, La experiencia de Tuluá. Colección Estudios del

Territorio. Bogotá, Escala S.A, 2007

18 Ibíd

19 GIMÉNEZ BALDRES, Enrique J. Op. Cit.

20 ANDER-EGG, Ezequiel. Métodos y técnicas de investigación social. Lumen, Humanitas, 2004 
Bucaramanga por parte de los entes de gestión municipal, situación que genera crecimientos incontrolados e insostenibles en el ámbito territorial, ambiental y económico. A partir de allí se plantean las siguientes de preguntas, referidas anteriormente:

\section{PREㄷㄴ NTA}

¿Las tendencias y los factores del crecimiento histórico de la ciudad han incidido en las condiciones actuales de los márgenes urbanos?
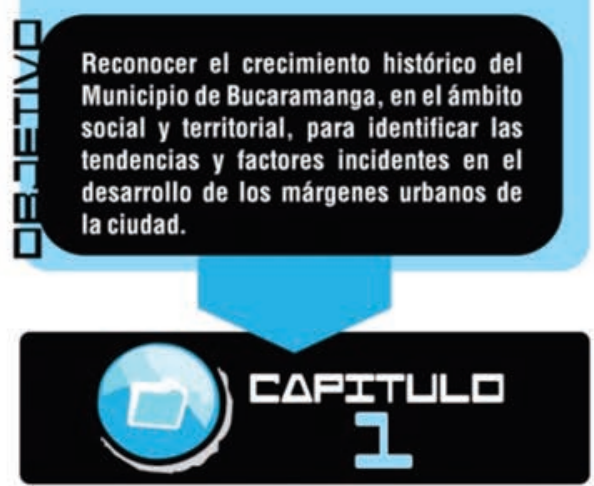

CRECIMIENTD HISTRICᄆ

\section{PREㄷㄴNTA}

¿Se han realizado intervenciones urbanas bajo el contexto periurbano que estructuren el crecimiento sostenible de la ciudad?

Referenciar intervenciones urbanas formuladas bajo el contexto periurbano que contengan similitudes con las oportunidades, problemáticas 0 debilidades diagnosticadas en el sitio a intervenir, con la intensión de obtener conclusiones acertadas para la formulación de la propuesta urbana.

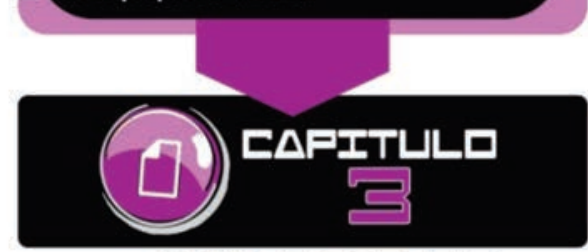

$\triangle N \Delta L I S I S$ ㅁE REFERENTES

\section{PRECㄴNTA}

¿Son los márgenes urbanos los espacios encargados de articular el crecimiento de la ciudad con su entorno?

Estudiar la situación de los márgenes urbanos de Bucaramanga para identificar Ios aspectos ambientales, físicos y las dinámicas socioeconómicas desarrolladas en este tipo de espacios periurbanos a fin de escoger uno de los márgenes que tras una intervención

II urbana potencialice y estructure el

crecimiento sostenible de su entorno.

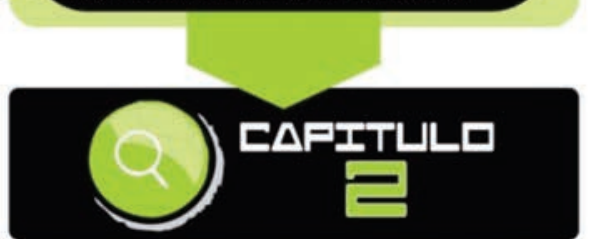

\section{RECNㅁImIENT DE 늗 $\mathrm{m} \triangle \mathrm{RE} E \mathrm{~N} E=$ பRE $\triangle N$ 므 DE EபLCRAM $\triangle N E \Delta$}

\section{PREㄷNTA}

¿El ordenamiento físico de las actividades y recursos de los márgenes urbanos basados en las características socio-económicas y ambientales del territorio permiten la potencialización y el crecimiento sostenible territorio periurbano?

Estructurar un ordenamiento físico de las diferentes actividades y recursos del margen seleccionado teniendo en cuenta las II características socio-económicas y respetando

Tlas condiciones ecológicas del entorno

III mediante la formulación de los lineamientos estratégicos de crecimiento sostenible.

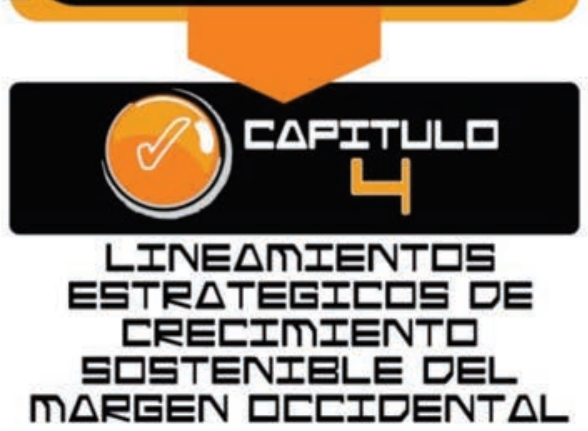

Imagen I. Esquema de la metodología. Fuente: Autoras del Proyecto 
Concretado el problema y las preguntas, la investigación parte a la fase de planeación de los objetivos, los objetivos específicos son quienes identifican el rumbo hacia el cual deben dirigirse los recursos y esfuerzos para dar cumplimiento al objetivo general, esta investigación se estructura con el fin de alcanzar el objetivo general mediante una serie de pasos denominados capítulos. Cada uno de los capítulos se fundamenta en cada uno de los objetivos específicos planteados para la investigación.

\section{ETAPAS COMO GUÍA PARA EL DESARROLLO INVESTIGATIVO DE LOS CAPÍTULOS FORMULADOS}

Para desarrollar las temáticas de los capítulos se diseñó un proceso guiado por etapas, el objeto de esta metodología es ordenar en una secuencia lógica las técnicas o herramientas utilizadas a lo largo de la investigación. Las etapas son las siguientes:

Cuadro I. Etapas del Proceso de Investigación

\begin{tabular}{|c|c|}
\hline Etapas & Actividades \\
\hline Formulación & $\begin{array}{l}\text { Tipo de Investigación } \\
\text { Técnicas de Trabajo }\end{array}$ \\
\hline Planeación & $\begin{array}{l}\text { Preparación y documentación } \\
\text { Formulación del esquema de acopio de datos } \\
\text { Preparación del programa de trabajo }\end{array}$ \\
\hline Recopilación de Datos & $\begin{array}{l}\text { Toma de datos } \\
\text { Clasificación y organización }\end{array}$ \\
\hline Procesamiento de Datos & $\begin{array}{l}\text { Análisis e interpretación de la información obtenida } \\
\text { Diagramación del análisis en las fichas técnicas }\end{array}$ \\
\hline Interpretación & Síntesis y establecimiento de las conclusiones \\
\hline
\end{tabular}

Fuente: Autoras del Proyecto

\section{CAPÍTULO I. UNA APROXIMACIÓN AL CRECIMIENTO URBANO HISTÓRICO DE BUCARAMANGA}

Este capítulo se organiza con un criterio documental, su objetivo es entender los fenómenos y factores influyentes en el crecimiento urbano de Bucaramanga, motivo por el cual la investigación adquiere un carácter de documentación histórica. "La investigación histórica analiza la trayectoria completa del objeto estudiado y su condicionamiento por los diferentes periodos e influencias a lo largo del tiempo"2l. El desarrollo del capítulo implica el estudio de las distintas etapas de crecimiento de la ciudad organizadas en intervalos cronológicos que parten de 1908 hasta el año 2005, estos intervalos permiten conocer la evolución y el desarrollo de la ciudad frente a los fenómenos económicos, sociales y políticos de cada época reflejados en el ámbito urbano.

$21 \quad$ BUNGE, Mario. La investigación científica: su estrategia y su filosofía. Barcelona, Siglo XXI, 1989 


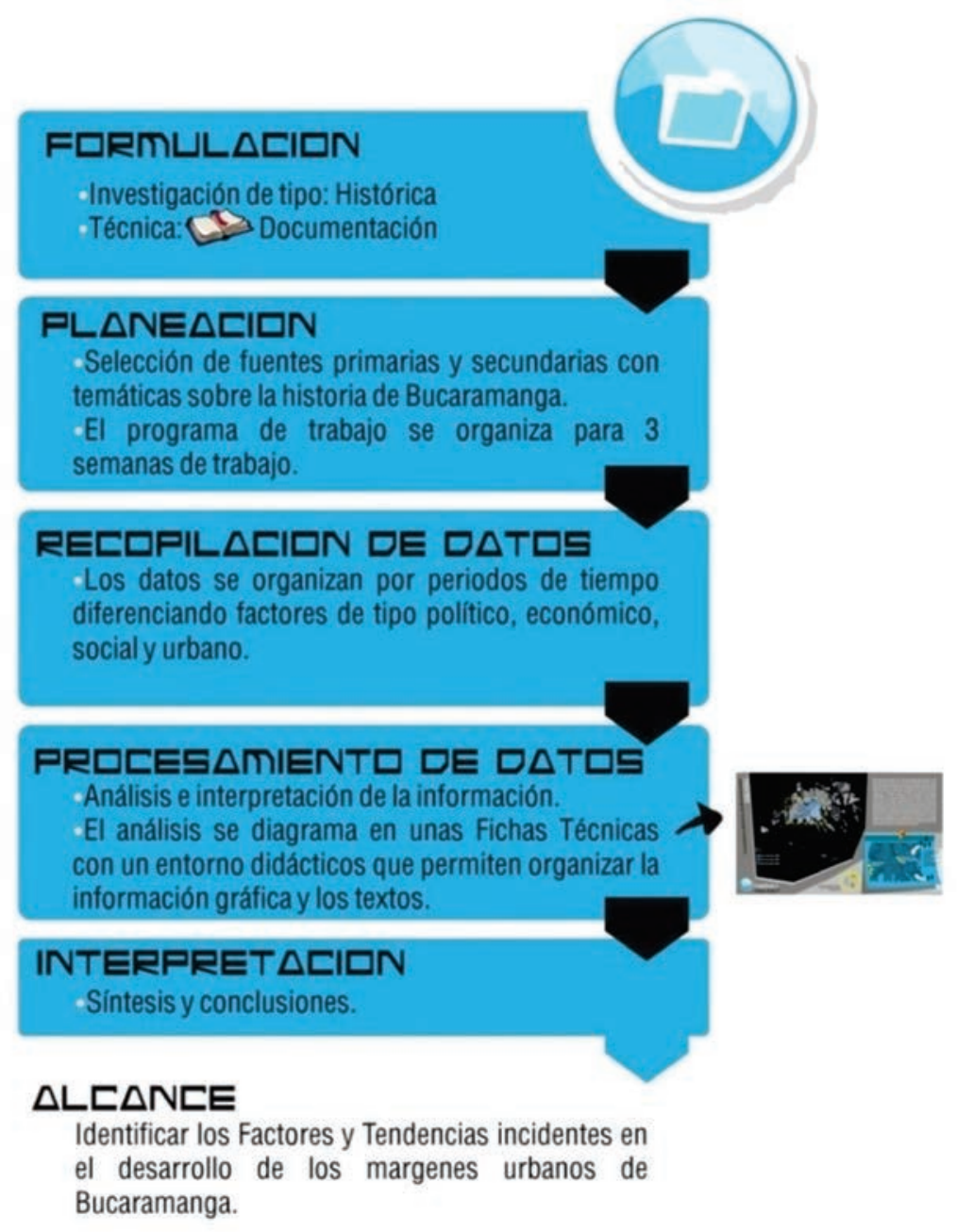

El transcurrir del tiempo trajo consigo la evolución y el crecimiento de lo que fueron asentamientos humanos hasta llegar a conformar ciudades con complejos sistemas sociales productoras de estructuras físicas y consumidoras de recursos naturales, es así, como entender la ciudad parte de comprender los procesos de transformación antrópica del territorio y las diversas expresiones sociales sobre el mismo. La ciudad funciona como un resultado cíclico entre su componente social y su componente físico, por ello la intervención o modificación del uno está directamente relacionada a una respuesta por parte del otro, la ciudad está en constante cambio, es dinámica, haciendo fundamental el estudio histórico de los factores sociales incidentes en los cambios físicos para comprender el territorio en todas sus dimensiones actuales. El seguimiento al crecimiento de la ciudad en términos físicos permite fijar los contornos históricos que surgieron como resultado de procesos sociales, más que establecer criterios de periodización es absolutamente necesario estudiar la producción de las formas espaciales a partir de la estructura social en la historia.

El concepto de margen nace de la pérdida de los límites urbanos debido al crecimiento de la ciudad, este proceso es constante pues reformula el margen y sus condiciones de periodo a periodo. Establecer los factores históricos influyentes en la generación de las condicio-
Figura 2. Etapas Metodología de Investigación Capítulo I. Fuente: Autoras del Proyecto 
nes existentes en los márgenes actuales de la ciudad, se torna como el objetivo principal del desarrollo de este capítulo, identificar las tendencias migratorias de las diversas clases sociales en los periodos de tiempo, establecer las acciones humanas sobre los ecosistemas existentes, identificar los factores que generaron las diversas actividades y usos de suelo, indagar por las intervenciones estatales en escenarios de margen y establecer las causas de la desarticulación espacial del margen con la estructura urbana, son las variables para identificar con el estudio al crecimiento histórico de la ciudad de Bucaramanga.

\section{EL INVESTIGADOR COMO EMISOR, LA COMUNIDAD COMO RECEPTOR, LAS FICHAS TÉCNICAS COMO HERRAMIENTAS PARA UNA EFECTIVA COMUNICACIÓN}

El aspecto más importante de investigar y producir conocimiento es encontrar la forma adecuada de expresar o compartir la información establecida con la comunidad interesada, el investigador como emisor y la comunidad como receptor, es así como el investigador entra en la labor de identificar el canal por el cual pretende comunicar la información, esta investigación plantea la comunicación gráfica como medio para compartir los datos obtenidos. Las fichas técnicas permiten de forma didáctica y gráfica organizar la información recolectada y elaborada, los textos explicativos permiten interpretar fácilmente los acontecimientos de cada uno de los periodos analizados junto a la ocupación gráfica del territorio, reflejada en la cartografía que con una escala de azules permite identificar las siluetas que forma la ciudad con su crecimiento histórico.

Ficha I. Crecimiento Histórico de Bucaramanga, Periodo de 1908 a 1928

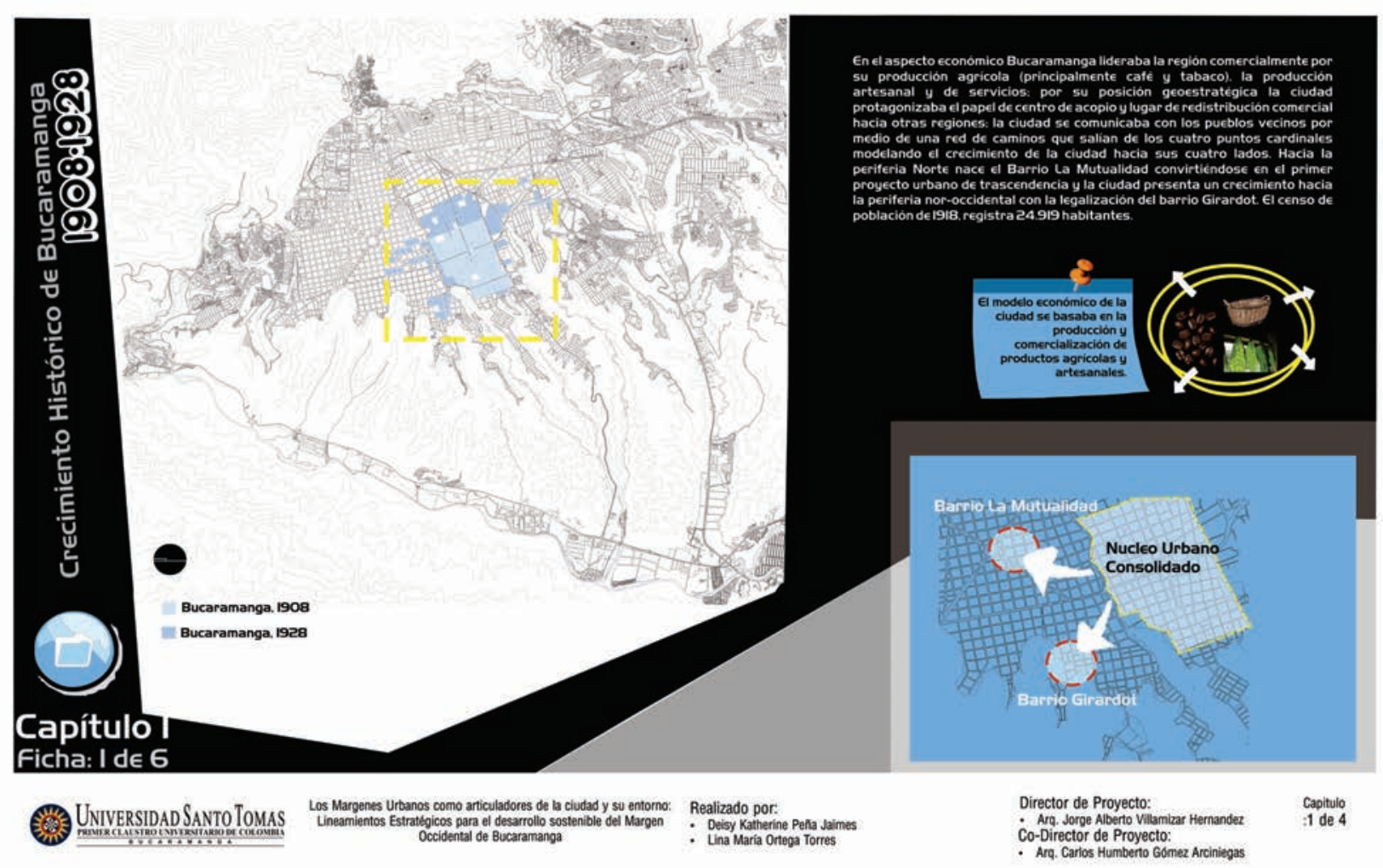




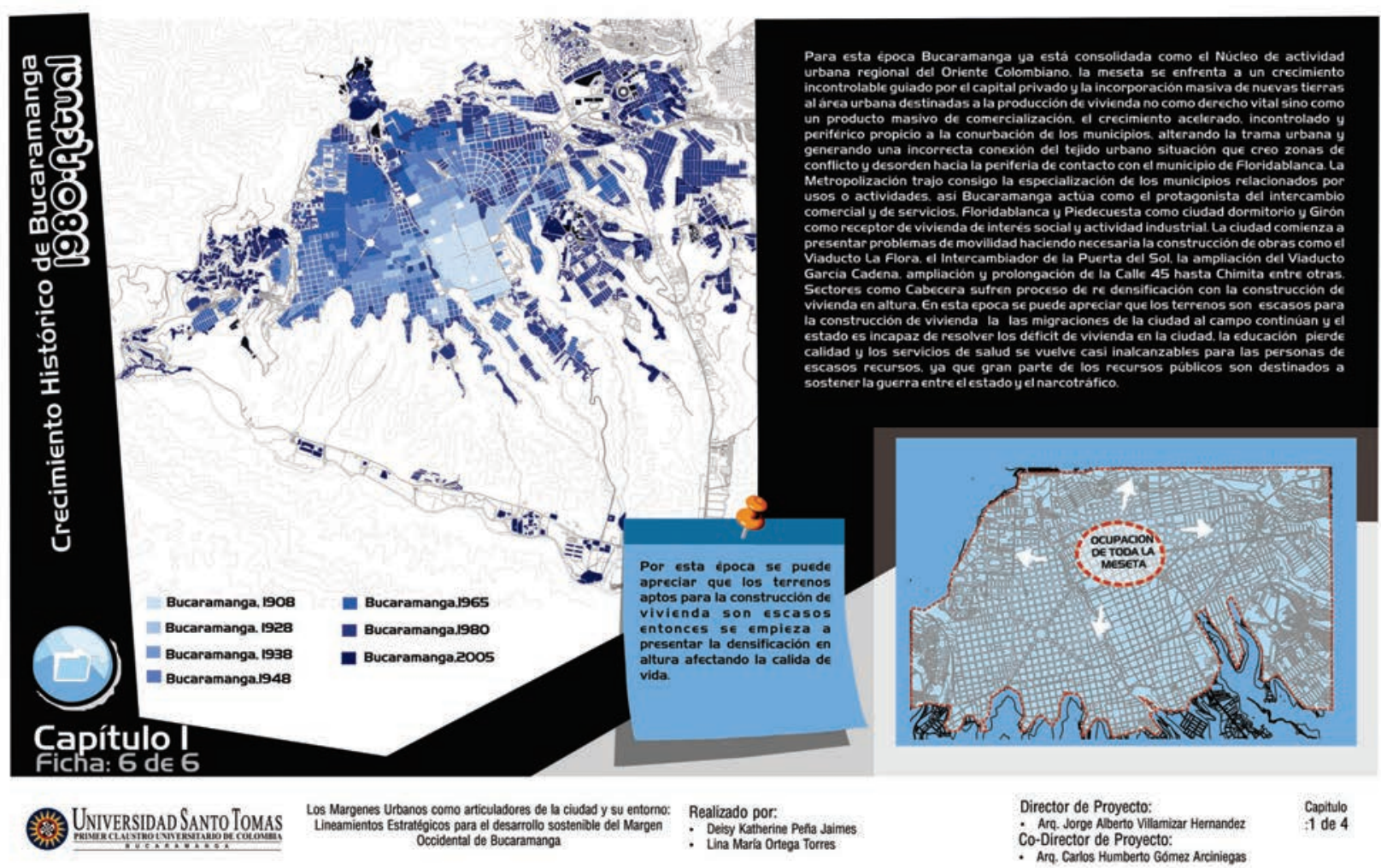

Fuente: Autoras del Proyecto

\section{DE LA RECOPILACIÓN DE DATOS A LA INTERPRE-TACIÓN DE LOS FENÓMENOS URBANOS INCIDEN-TES EN EL CRECIMIENTO HISTÓRICO DE LA CIUDAD}

El principal factor generador de migraciones campo-ciudad, es la violencia, cada época bajo un contexto político y económico diferente ha marcado la frecuencia e intensidad de las movilizaciones. La concentración de migrantes de bajos recursos conllevó a la explosión demográfica de la ciudad en un territorio incapaz de soportarlo, lo que generó asentamientos subnormales en terrenos baratos y residuales generalmente ubicados en la periferia de la ciudad y con amenazas naturales. Los asentamientos están cargados de problemáticas en el ámbito social, ambiental y económico. Respecto a las problemáticas sociales, los asentamientos presentan desintegración del núcleo familiar, aumento en los índices de violencia intrafamiliar, embarazos en adolescentes, auge de vicios y delincuencia; fundamentados en la inaccesibilidad a la educación y a fuentes de empleo formales. Los asentamientos son una fuerte carga para el sistema ambiental de la ciudad, ya sea por su ubicación en ecosistemas frágiles como por el vertimiento de aguas servidas en corrientes de agua sin tratamiento alguno. 
Podemos observar que el ICT fue el ente público que mayor participación tubo en el direccionamiento del crecimiento de la ciudad, su intervención siempre incitó a la ocupación de las periferias de la ciudad en cada época histórica. Su desaparición a finales de la década del 80, la transición del ICT al INURBE, la final desaparición del INURBE con el Decreto 554 de 2003 y las nuevas políticas de subsidios de vivienda social, marcaron la desaparición de la acción pública en los procesos de planificación y desarrollo del territorio, así como se frenó la cobertura de vivienda digna para la población vulnerable y se propició la legalización de asentamientos subnormales en terrenos con amenazas naturales en áreas de periferia.

Hacia la época de los 80 la ciudad desarrolló un crecimiento por enlace con el municipio de Floridablanca, Girón y posteriormente Piedecuesta, que trajo consigo el fenómeno urbano de la conurbación y la integración de los sistemas de cada municipio, en 198I Bucaramanga, Floridablanca y Girón conformaron el Área Metropolitana de Bucaramanga -AMB- posteriormente en 1984 Piedecuesta entró a hacer parte del AMB. La situación tiende a acentuarse ya que Bucaramanga lidera en cuanto a economía, servicios y mercados se trata, lo que genera una polarización en el mercado respecto a la relación con otras regiones y en cuanto al desarrollo de la región; esto crea un flujo libre de personas, de bienes y de servicios por el territorio, conceptualizado como Ciudad-Región. Entre los beneficios de este fenómeno puntualmente hablando de Bucaramanga, podemos referenciar que los municipios cercanos, Floridablanca, Girón y Piedecuesta, se vean favorecidos por una demanda efectiva de sus productos. Pero entre las cargas impuestas por dicho fenómeno podemos citar el fuerte impacto ambiental, el excesivo consumo de recursos naturales en un solo lugar del territorio y la situación de conflicto y desorden en los bordes de los municipios conurbados. La demanda constante de terrenos para urbanizar conlleva a la pérdida de suelos agrícolas y áreas verdes por áreas de expansión urbana incontrolada periférica para usos residenciales e industriales, situación que genera un crecimiento insostenible en términos de recursos naturales.

\section{CAPÍTULO 2. RECONOCIMIENTO DE LA DIVERSIDAD DE ACTIVIDADES, USOS Y FENÓMENOS URBANOS EN LOS MÁRGENES DE BUCARAMANGA}

Los procesos desarrollados en este capítulo parten del reconocimiento vivencial del territorio, por lo tanto, se clasifica como una investigación de campo.

"Este proceso de investigación se basa en informaciones obtenidas directamente de la realidad, permitiéndole al investigador cerciorarse de las condiciones reales en que se han conseguido los datos"22.

Para entender la complejidad del margen urbano es necesario el reconocimiento de las condiciones y relaciones existentes entre sus componentes urbanos, rurales y ambientales, el margen es una franja territorial con procesos diversos condicionados por la mezcla de sus del suelo urbano y rural así como la presencia de ecosistemas vulnerables.

Este capítulo se desarrolla mediante trabajo de campo, estudio y análisis; herramientas que permiten la sensibilización e interacción directa con las realidades expuestas en los márgenes. La observación es quizá la actividad más importante para el reconocimiento de las condiciones físicas y sociales del entorno, para ello se genera una base de datos

22 SABINO, Carlos. El proceso de Investigación. Bogotá, Editorial Panamericana, 1992 
fotográfica con aproximadamente 400 fotografías por margen, la observación permite el registro informal de conductas y actividades condicionadas por el lugar. Para el desarrollo del capítulo se diseñan dos fases de trabajo, en la primera fase tiene como alcance reconocer las relaciones y condiciones existentes en los márgenes urbanos de Bucaramanga la segunda fase tiene como alcance la identificación y el diagnóstico del margen con mayor impacto negativo en el territorio.

Figura 3. Etapas Metodología de la Investigación Capítulo 2.

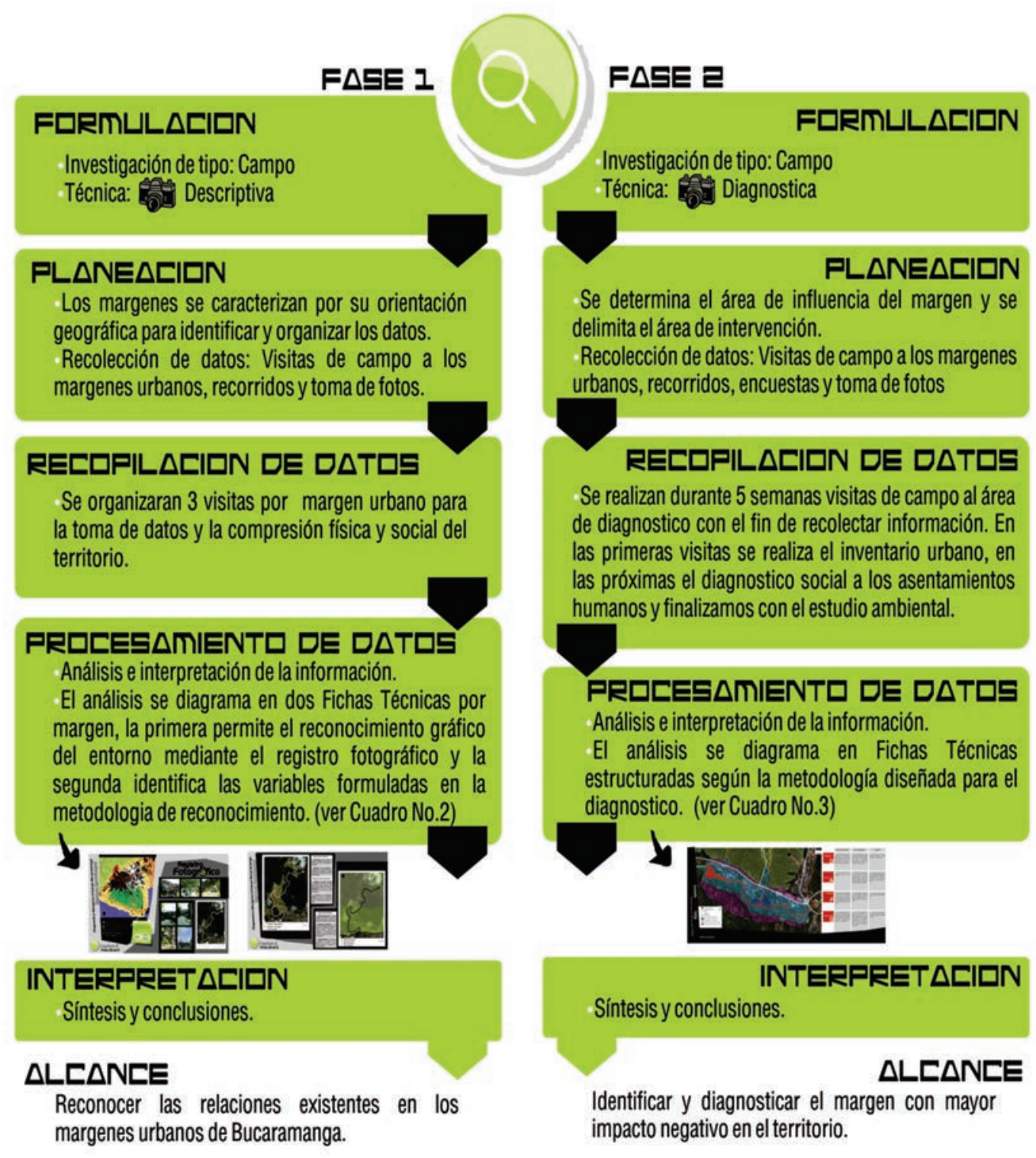

Fuente: Autoras del Proyecto 


\section{CAPÍTULO 2 - FASE I. RECONOCIMIENTO DE LOS MÁRGENES URBANOS DE BUCARAMANGA}

Figura 4. Fase I Reconocimiento de los márgenes urbanos de Bucaramanga. Fuente: Autoras del Proyecto

Margenes Urbanos

Componente Rural de Bucaramanga Escarpa Occidental de Bucaramanga Municipio de Girón

Municipio de Floridablanca

- Vias Principales

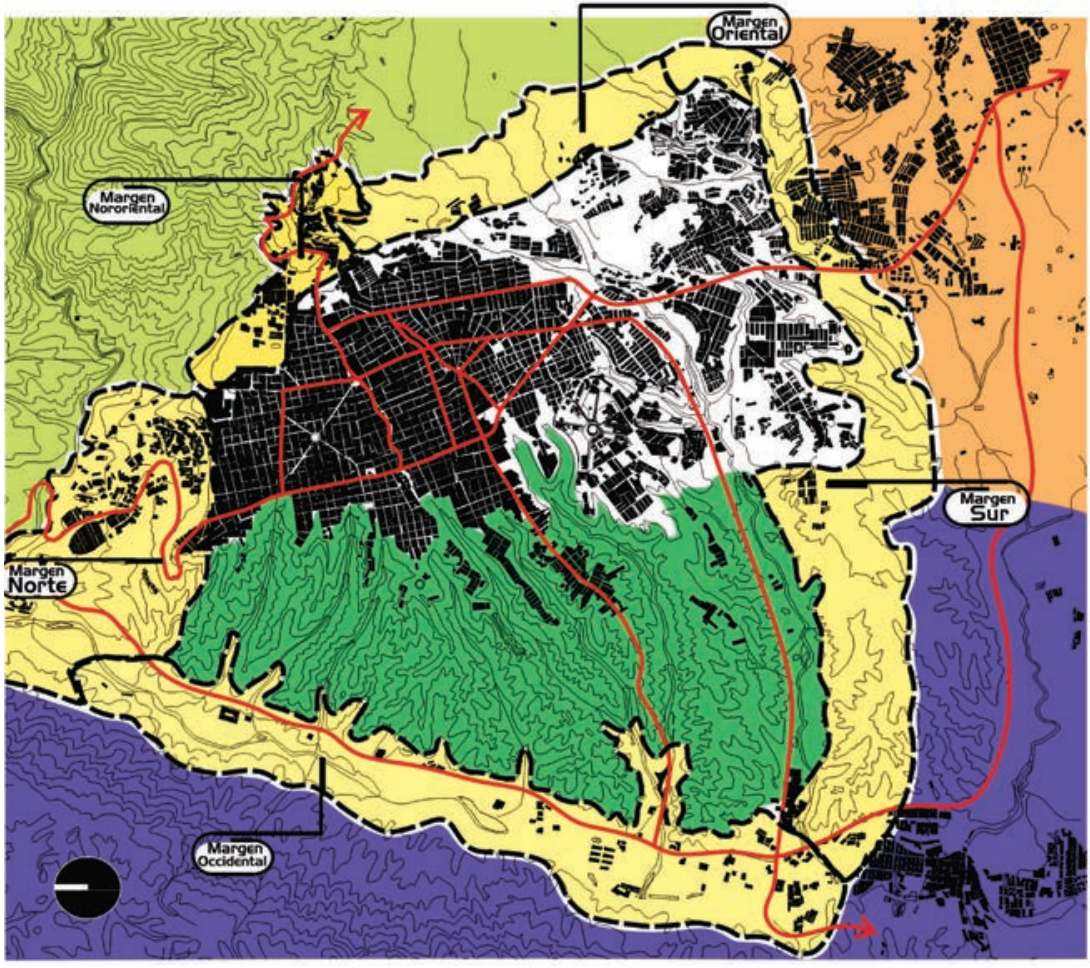

El paso inicial para la recolección de datos de la fase I es la caracterización de los márgenes de Bucaramanga por su orientación geográfica, es así como se identifican 6 márgenes de reconocimiento, Norte, Nororiental, Oriental, Sur y Occidental. El Trabajo de campo parte de un reconocimiento inicial del territorio con la intención de explorar e identificar las variables de la investigación, se realizaron 3 visitas constantes a cada margen, lo que permitió la formulación de nuevas opiniones para la comprensión espacial (topografía, sistema ambiental, estructura urbana) y social (dinámicas socio-económicas) del territorio. El procesamiento de los datos obtenidos se organiza por medio de fichas técnicas que permiten el análisis e interpretación de datos de forma didáctica, estas fichas se estructuran mediante las siguientes variables.

Cuadro 2. Estructura de las fichas técnicas para el reconocimiento de los márgenes urbanos

\begin{tabular}{|c|c|}
\hline \multicolumn{2}{|r|}{ Variables } \\
\hline Relaciones existentes & $\begin{array}{l}\text { Componente Urbano } \\
\text { Componente Rural } \\
\text { Sistema Ecológico }\end{array}$ \\
\hline Aspecto Físico (Antrópico) & $\begin{array}{l}\text { Trama Urbana } \\
\text { Morfología de las Manzanas }\end{array}$ \\
\hline Aspecto Físico (Natural) & $\begin{array}{l}\text { Cuencas y Microcuencas } \\
\text { Ecosistemas Estratégicos } \\
\text { Amenazas Naturales }\end{array}$ \\
\hline Dinámicas Socio-Económicas & $\begin{array}{l}\text { Actividades de Consumo: Vivienda y Equipamientos } \\
\text { Actividades de Intercambio: Comercio } \\
\text { Actividades de Producción: Industria. }\end{array}$ \\
\hline
\end{tabular}

Fuente: Autoras del Proyecto 
La variables determinadas para las dinámicas Socio-Económicas se fundamentan en la concepción de ciudad planteada por Manuel Castells, de tal forma que la ciudad es el reflejo de los aspectos sociales y físicos desarrollados en el territorio ${ }^{23}$, el aspecto social referencia las actividades intangibles pero perceptibles y condicionantes de las dinámicas del entorno, entendidas como los tipos de relaciones entre los actores, relaciones de intercambio, de consumo y de producción.

Los márgenes urbanos de Bucaramanga protagonizan una dinámica de transformación del espacio rural al urbano que se caracteriza como un proceso de asentamiento desordenado y funcionalmente desarticulado de la estructura urbana de la ciudad, que genera viviendas informales algunas ya consolidadas con el tiempo. Los márgenes son escenarios de explosión demográfica por excelencia pues generan una gran tensión social por las demandas insatisfechas de equipamientos, servicios e infraestructura. En el reconocimiento realizado, se identifica que en el $80 \%$ de los espacios catalogados como márgenes urbanos de la ciudad presenta asentamientos informales y pobreza, que demuestra la ausencia de la planificación de los márgenes o periferias de la ciudad. La falta de planeación del crecimiento de la ciudad y, por ende, de sus márgenes, desencadena problemáticas ambientales. La contaminación de los ríos y las quebradas con el vertimiento de aguas sin tratamiento por falta de infraestructura, la invasión de bosques y espacios agrícolas para anexarlos al componente urbano, el consumo exagerado de recursos naturales por parte de una ciudad en constante crecimiento, la desestabilización de taludes por implantaciones inadecuadas en los terrenos y el auge de la erosión por tala de árboles en zonas pendientes.

Una vez reconocidas las condiciones existentes en cada margen, se realiza una evaluación mediante una matriz para identificar el margen que mayor impacto negativo genera en el territorio. La metodología aplicada a la matriz de evaluación califica las variables analizadas en el reconocimiento de los márgenes urbanos: Aspecto Físico Natural, Aspecto Físico Antrópico y Dinámicas socioeconómicas; en una escala de I a 3 donde se califica el tipo de impacto generado, I impacto positivo, 2 impacto negativo mitigable, 3 impacto negativo. Cada margen adquiere una calificación sumada de los números anteriormente evaluados, el margen que obtenga el número de mayor cifra es el que mayor impacto negativo genera en el territorio.

Cuadro 3. Matriz de Análisis Impacto generado por los márgenes urbanos en el territorio

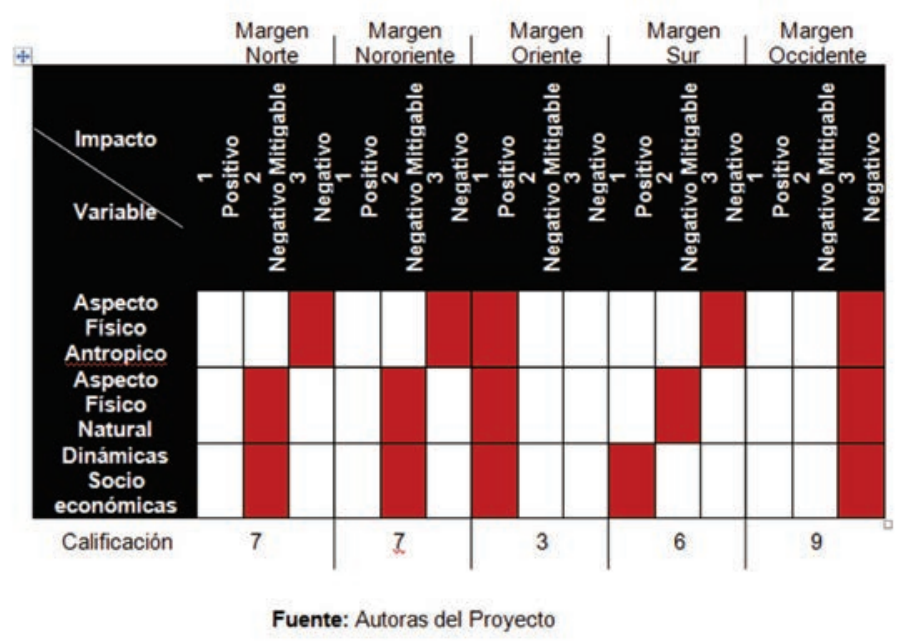

23 CASTELLS, Manuel. La Cuestión Urbana. México, Siglo XXI Editores, 1978 
Tras el Reconocimiento realizado a los márgenes urbanos de Bucaramanga, se establece que el Margen Occidental genera fuertes impactos en el territorio que afectan el bienestar de los habitantes de los municipios de Bucaramanga y Girón.

Ficha 3. Reconocimiento Márgenes Urbanos de Bucaramanga, Margen Occidental. Ficha $5^{a}$.

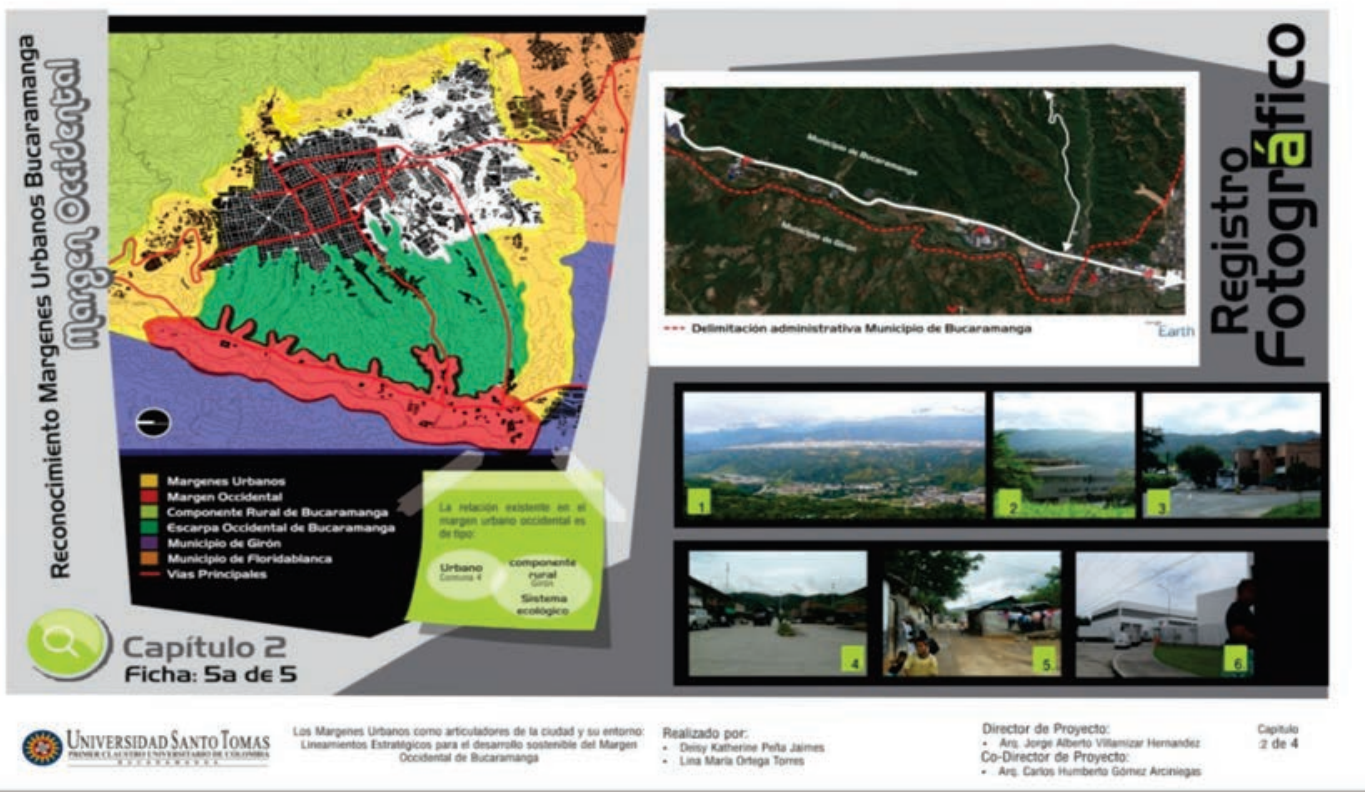

Fuente: Autoras del Proyecto

Ficha 4. Reconocimiento Márgenes Urbanos de Bucaramanga, Margen Occidental. Ficha 5b

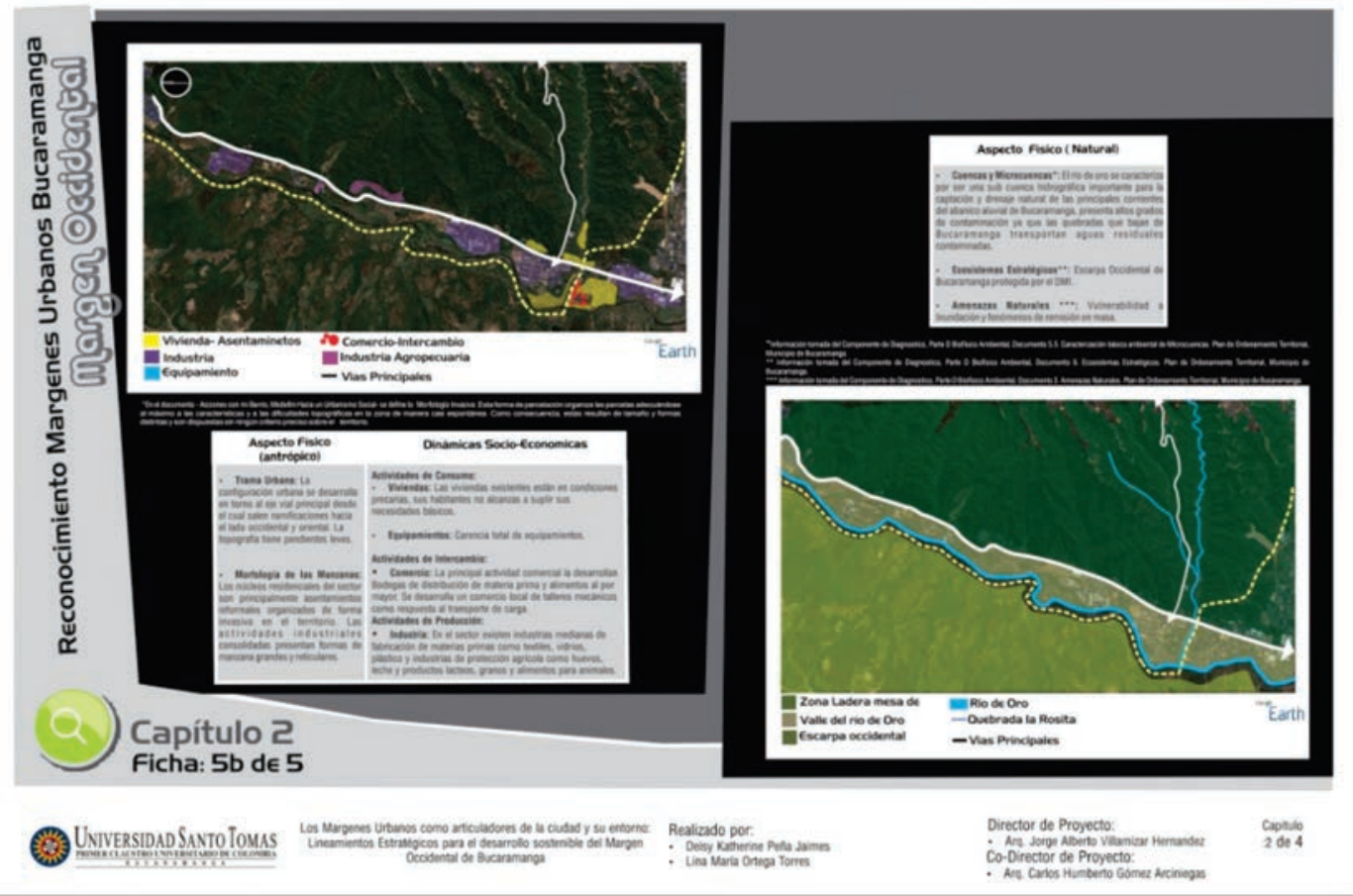

Fuente: Autoras del Proyecto 


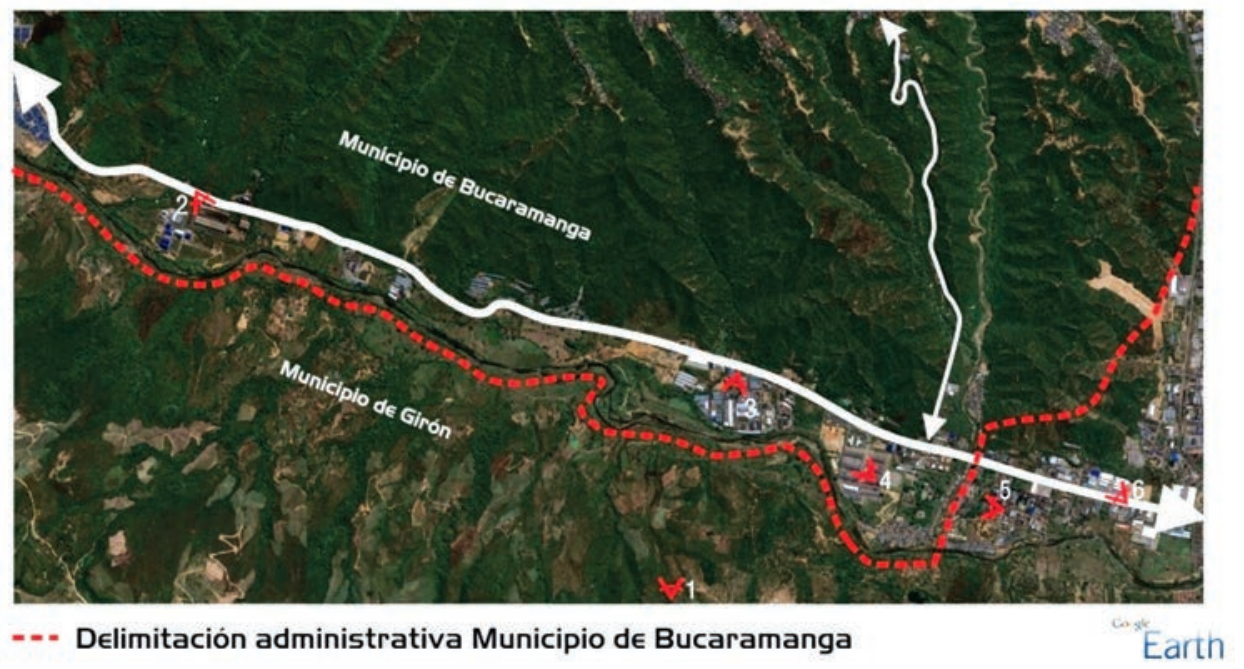

Fotografía I. Ubicación en el territorio Occidental. Fuente: Autoras del Proyecto, Google Earth

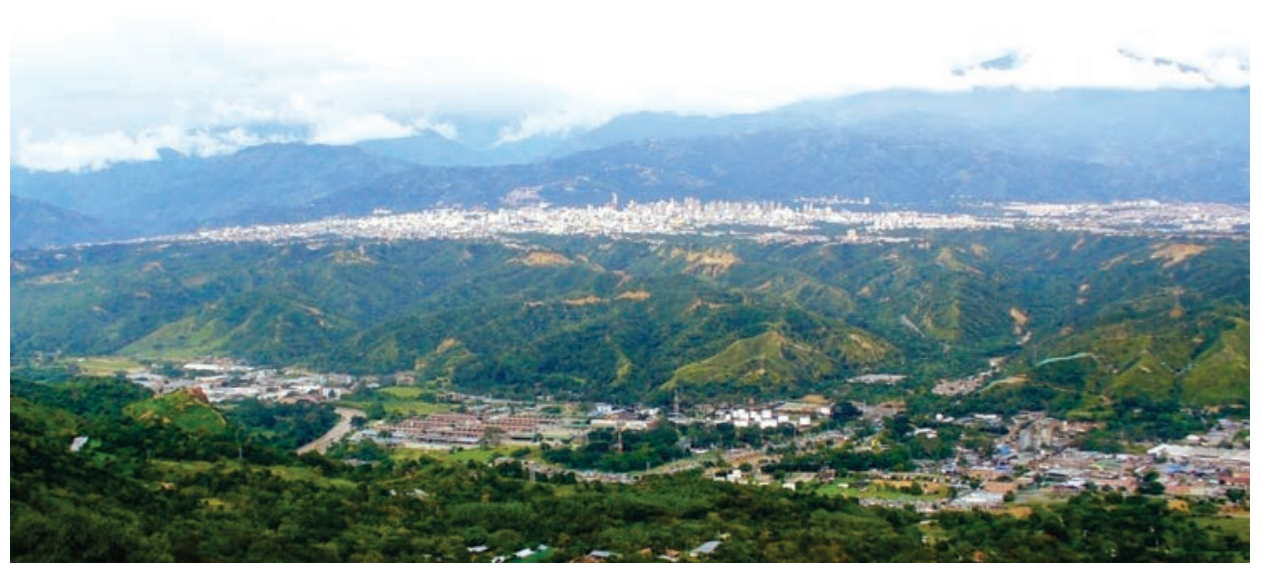

Fotografía 2. Reconocimiento al Margen Occidental, panorámica arriba abanico aluvial de Bucaramanga, abajo valle del Río de Oro. Fuente: Autoras del Proyecto

Fotografía 3. Reconocimiento al Margen Occidental, foto interior parque industrial. Fuente: Autoras del Proyecto

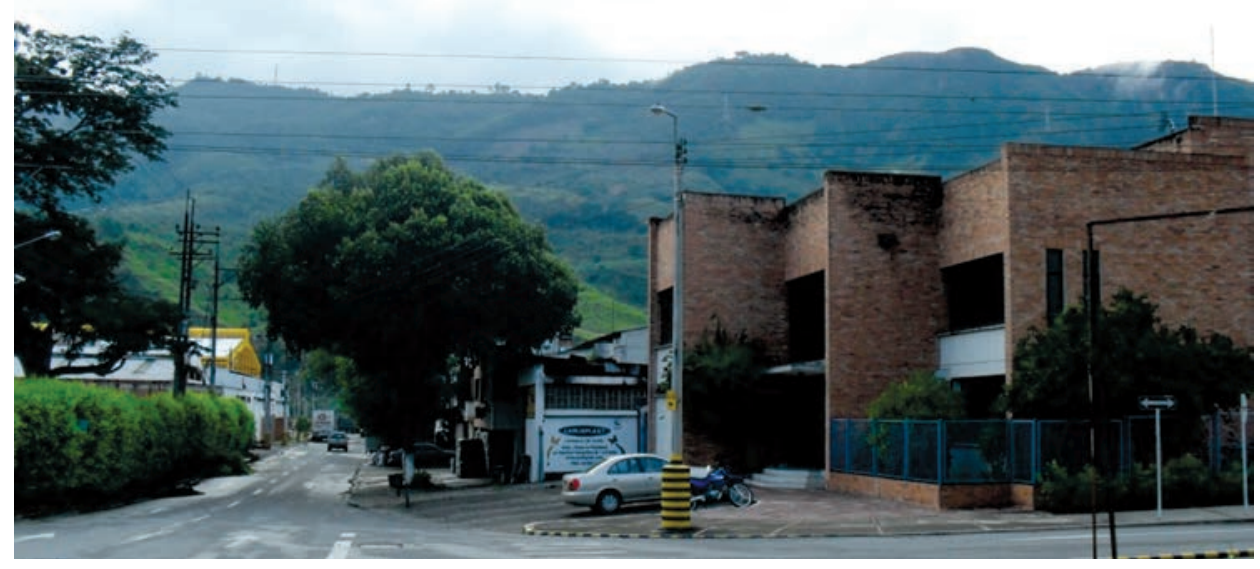

\section{165}


Fotografía 4. Reconocimiento al Margen Occidental, dinámica interna de Centroabastos. Fuente: Autoras del Proyecto

Fotografía 5. Reconocimiento al Margen Occidental, asentamientos informales en el área inundable del Río de Oro. Fuente: Autoras del Proyecto
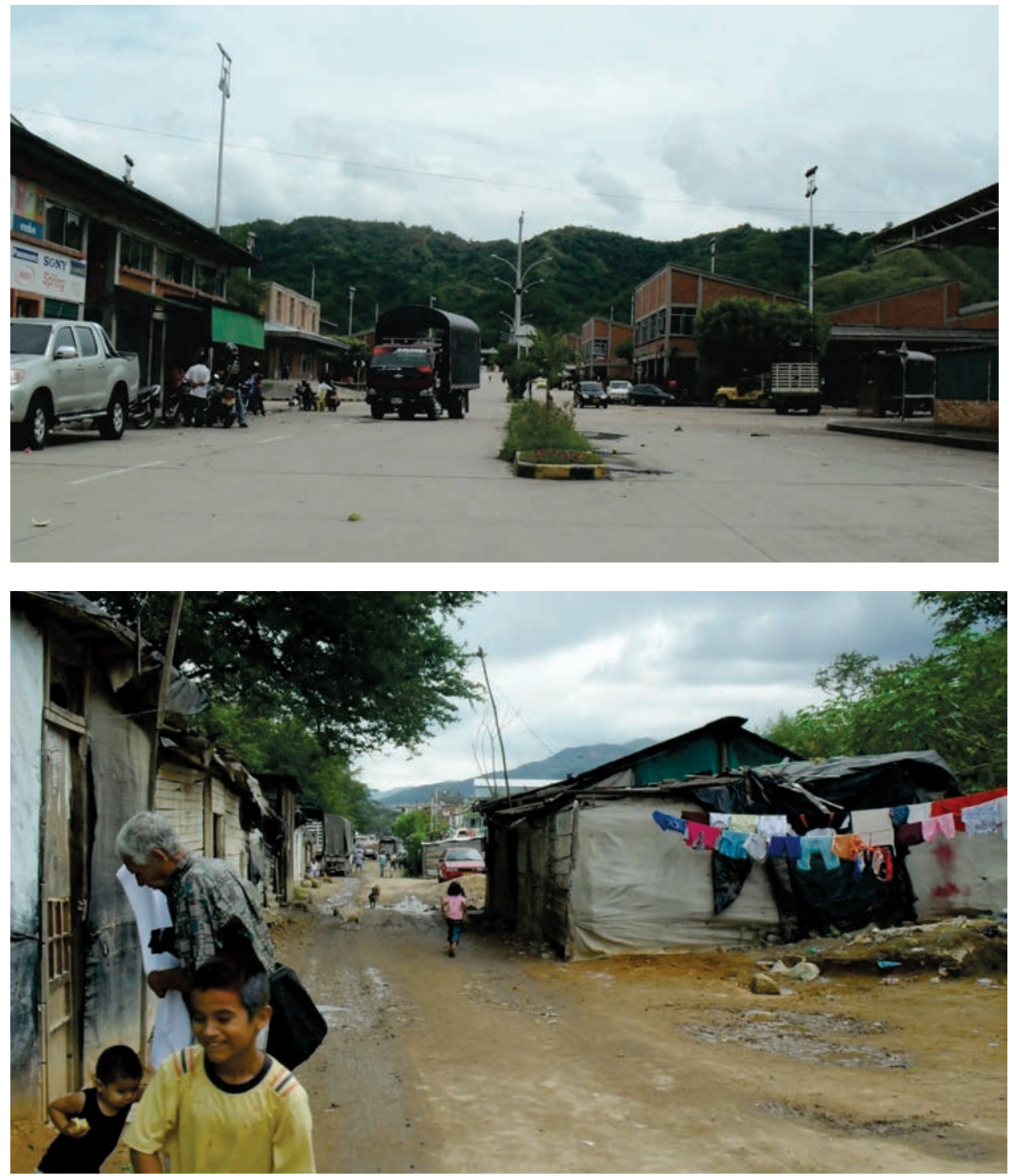

Fotografía 6. Reconocimiento al Margen Occidental, industrias del sector. Fuente: Autoras del Proyecto

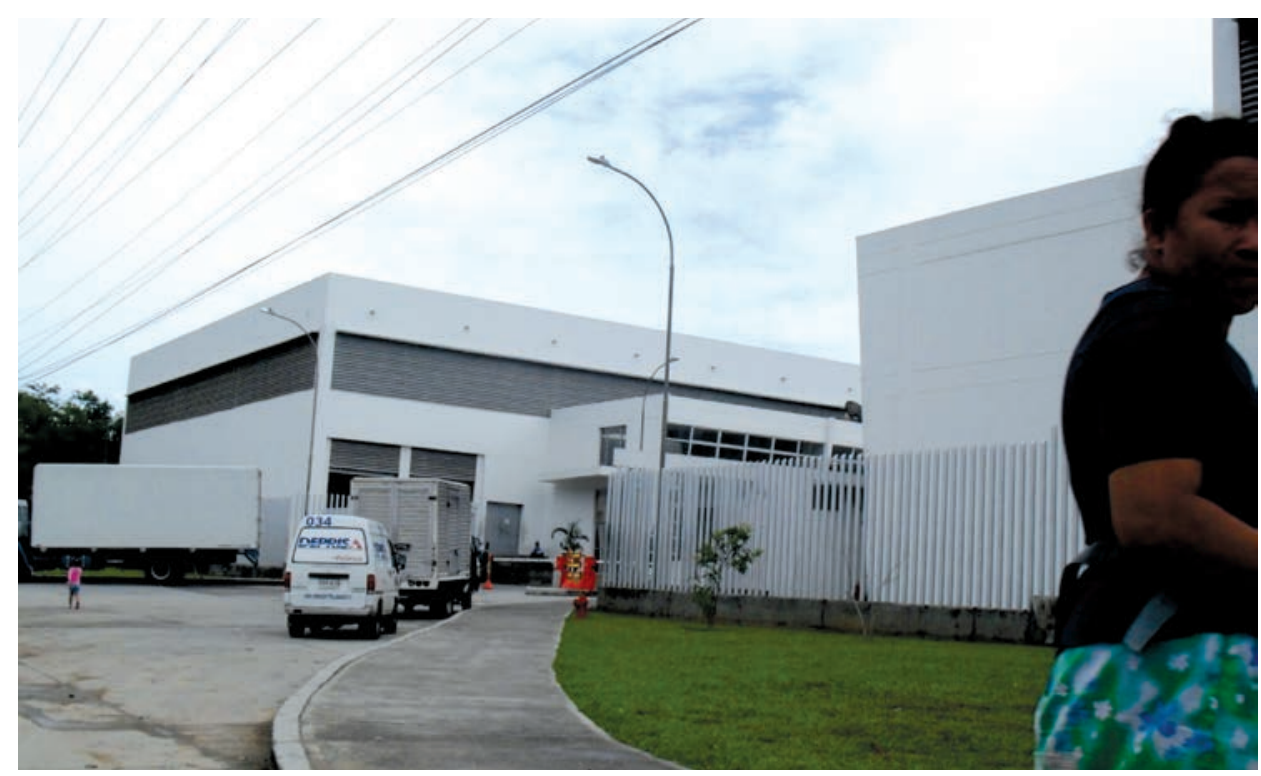




\section{CAPÍTULO 2 - FASE 2. MARGEN DE INTERVENCIÓN}

Tras analizar las condiciones presentes en cada margen la investigación pasa a la fase 2 luego de que por medio de una matriz de selección se identifica el margen que mayor impacto negativo genera en el territorio y que tras una intervención urbana estructure el crecimiento sostenible de su área de influencia, margen al cual se le realizará un inventario urbano de los actores físicos encontrados en el territorio y posteriormente el diagnóstico de sus componentes estructurado según el siguiente cuadro:

Cuadro 4. Estructura Diagnóstico Margen de intervención

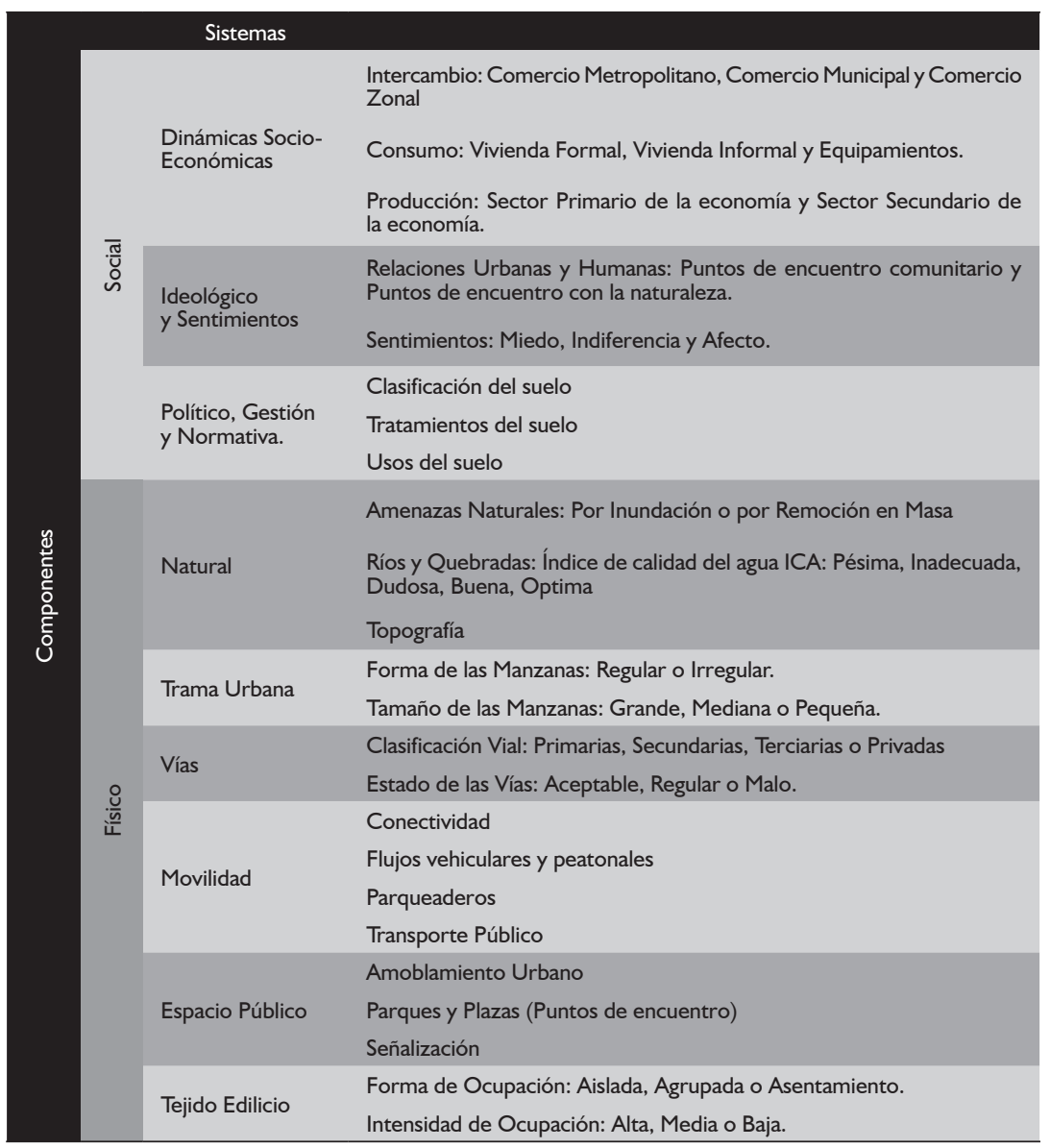

Fuente: Autoras del Proyecto

Tras el Reconocimiento realizado a las márgenes urbanas de Bucaramanga, se establece que el Margen Occidental presenta oportunidades y problemáticas importantes que influencian y afectan el bienestar de los habitantes de los municipios de Bucaramanga y Girón. El sector catalogado como margen urbano representa un escenario estratégico que jalona el desarrollo socio económico del $\mathrm{AMB}$ y es un ecosistema vital que tras acciones antrópicos se encuentra en lamentables condiciones. La interfaz periurbana generalmente se caracteriza por la convergencia de jurisdicciones municipales, en este caso Bucaramanga y Girón, se 
hace necesaria la articulación permanente de los entes de gestión de cada municipio y la formulación de políticas que organicen y estructuren el desarrollo sostenible del territorio ocupado por los municipios que conforman el AMB.

Para delimitar el área de influencia se tienen en cuenta los siguientes aspectos:

- Área de drenaje del Río de Oro, conformado por las quebradas que bajan por la escarpa occidental y depositan aguas residuales al cauce del Río de Oro así como la micro cuenca de la Quebrada La Iglesia y Río Frío.

- Falda Oriental del Cerro Palonegro, (cotas de pendiente moderada, áreas de inundación media).

- Vía principal (Anillo Vial - Autopista Café Madrid Palenque - Vía Girón Bucaramanga) por la tensión urbana que genera la similitud de actividades y situaciones presentes en el territorio.

Ficha 5. Ficha Técnica Componente Social, Sistema Dinámicas Socioeconómicas

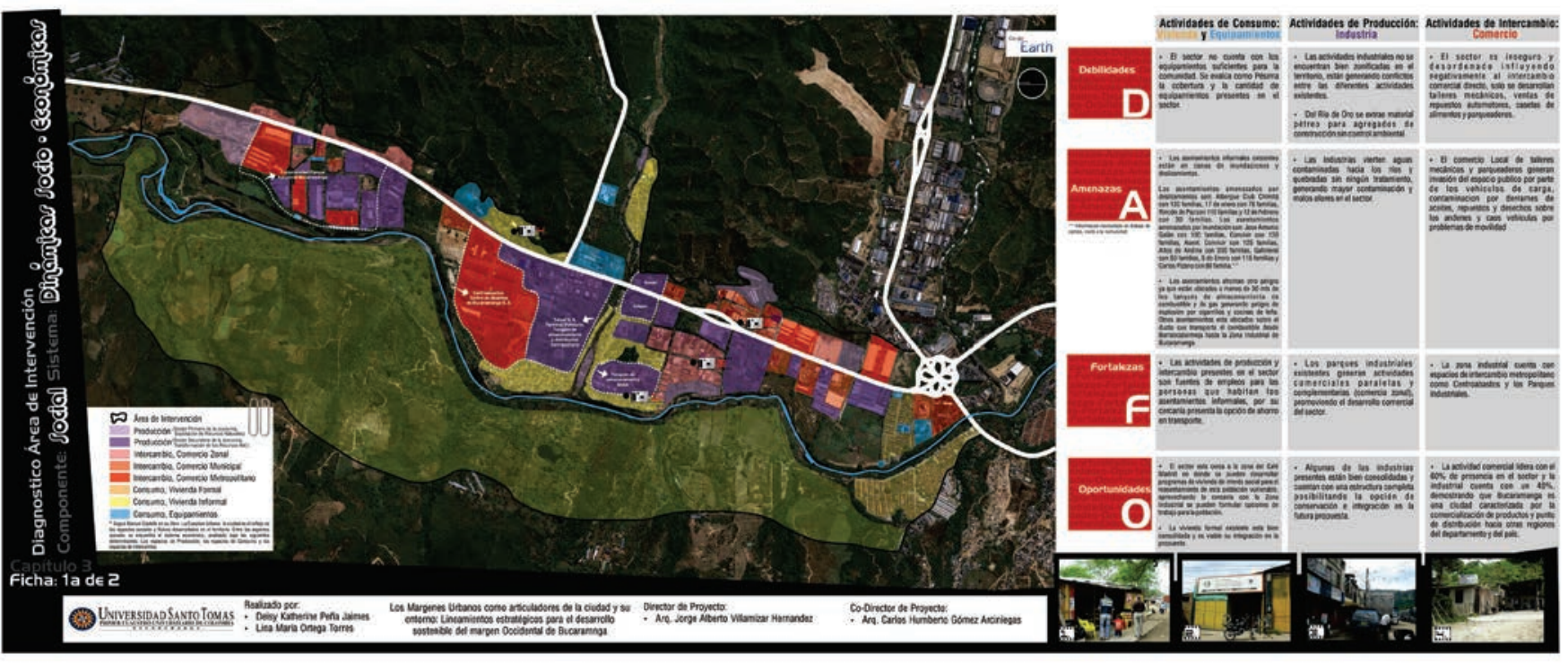

Fuente: Autoras del Proyecto 
Ficha 6. Ficha Técnica Componente Físico, Sistema Movilidad

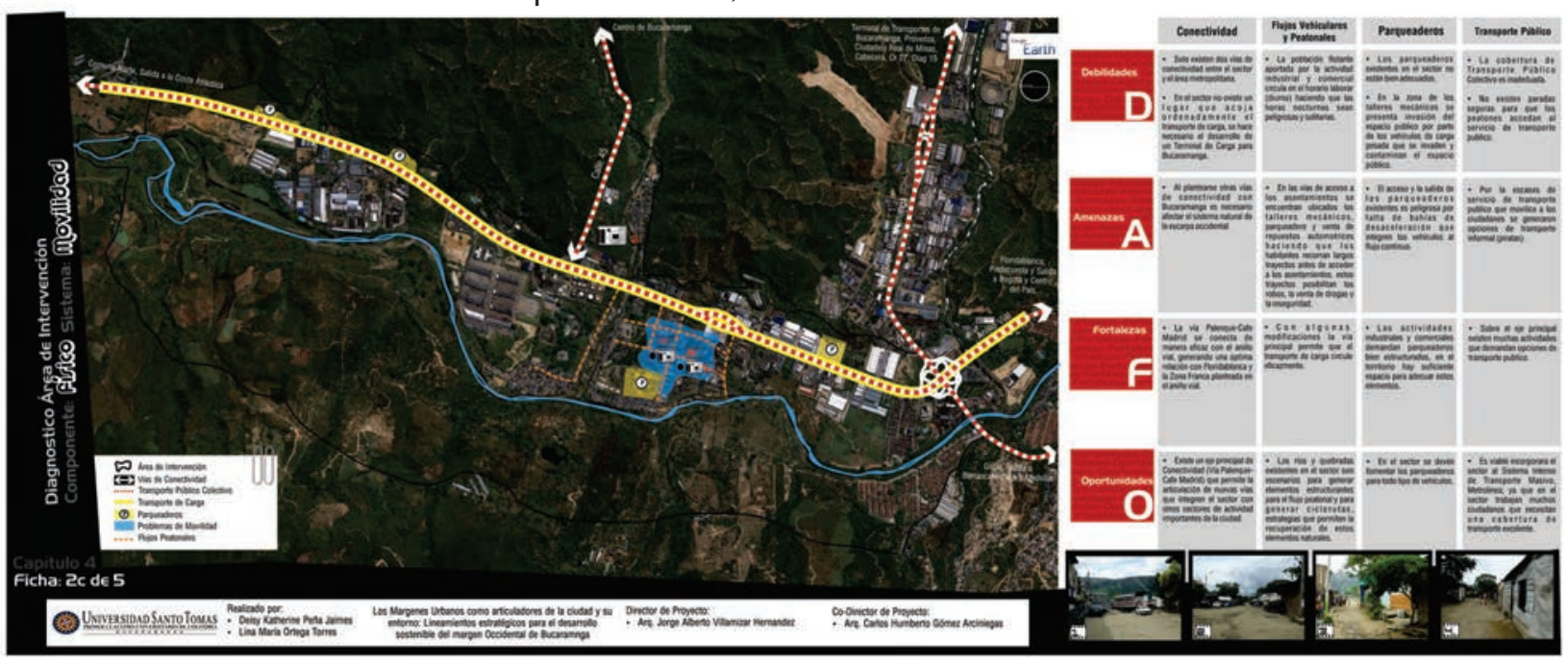

Fuente: Autoras del Proyecto

\section{OPORTUNIDADES Y CONFLICTOS, RESULTADOS DE UN DIAGNÓSTICO, DETERMINANTES DE UNA SOLUCIÓN}

El área diagnosticada se identifica como un Área Periurbana implantada en la unidad de paisaje determinada por el Valle del Río de Oro caracterizada por presentar actividades industriales, agroindustriales, comerciales y de protección ambiental; ubicada al Occidente del municipio de Bucaramanga y al Nororiente del municipio de Girón y organizada sobre un eje vial de carácter metropolitano (Vía Palenque-Café Madrid). El estado de deterioro físico y social del sector permite el desarrollo de vivienda informal en zonas con amenazas naturales y el desarrollo de actividades delictivas, el ecosistema está altamente contaminado ya que el Río de Oro es el afluente de drenaje de las aguas residuales e industriales sin tratamiento de Bucaramanga, Girón y Floridablanca.

\section{Oportunidades}

- Existen dos núcleos residenciales consolidados que están directamente relacionados a la Zona Industrial, el núcleo residencial de Girón y el núcleo residencial de la Comuna I y 2 de Bucaramanga.

- El territorio circundante a estos núcleos residenciales permite la opción de formular proyectos de vivienda que acoja a la población de los asentamientos a reubicar presentes en la Zona Industrial.

- La construcción de la Zona Franca de Santander en el anillo vial y el Centro Logístico sobre la vía Palenque -Café Madrid generan una fuerte tensión en el territorio.

- A causa de la tensión generada el sector fortalece su vocación industrial, es necesario que el perfil vial (Palenque-Café Madrid) adopte bahías de desaceleración para que los vehículos de carga pesada accedan a las industrias sin generar conflicto vial.

- La zona de actividad implantada en el Valle del Río de Oro está catalogada como una de las áreas funcionales estructurantes del modelo territorial formulado por el POT para el municipio de Bucaramanga. 
- Con la intervención urbana se busca integrar y otorgar las facultades al territorio para que funcione como un área sostenible e integral.

- La normativa formula una ronda de protección a las quebradas de $30 \mathrm{~m}$ y a los ríos de $50 \mathrm{~m}$ medidas a partir de la cota de inundación así como la protección a ecosistemas estratégicos como el DMl y los bosques de protección.

- Estos espacios son propicios para intervenciones de recuperación y conservación mediante escenarios de espacio público.

- En el sector ya existen actividades industriales, agroindustriales y comerciales lo suficientemente consolidadas y vinculadas a las dinámicas económicas del Área Metropolitana

- Es necesario plantear una red óptima de movilidad que permita la interacción entre las actividades existentes y las propuestas así como la relación armoniosa con el componente ambiental.

\section{Conflictos}

- El Río de Oro y las Quebradas que desembocan en él tienen índices de Pésima e Inadecuada en cuanto a calidad del agua, esto se debe a que estas quebradas y el río son el sistema de drenaje de las aguas residuales e industriales.

- Es necesario plantear estrategias de tratamiento en la fuente para las aguas servidas y se formula la opción de generar pequeñas cascadas que dinamicen y oxigenen el agua para mejorar su estado.

- El sector presenta una deficiencia en equipamientos, aunque es un sector de vocación industrial son necesarios equipamientos para la comunidad que labora allí y para las viviendas cercanas.

- Se plantea la opción de generar áreas de recreación, equipamientos de salud, de educación y capacitación.

- En el imaginario colectivo de los habitantes de la ciudad, el sector está catalogado como peligroso, sucio y desordenado. La presencia de talleres mecánicos aportan contaminación y desechos a las calles.

- Es necesario cambiar la idea de que el desarrollo de actividades industriales propician el desorden y la contaminación, la organización de las actividades y la planeación estratégica del territorio permiten que las actividades se desarrollen en condiciones humanas y dignas.

- En el sector se ubican II 26 familias en condiciones lamentables, afrontan peligros por amenazas naturales $y$ viven en condiciones precarias que hacen necesaria su reubicación.

- Se plantea la opción de formular planes de vivienda de interés social en el territorio cercano al Café Madrid con condiciones dignas de vivienda y espacios colectivos.

- La desarticulación administrativa de los municipios genera problemas de planeación del territorio.

- Es necesaria la formulación y aplicación de un POT metropolitano como mecanismo de planeación y ordenamiento del territorio. 


\section{CAPÍTULO 3. DOCUMENTACIÓN EXPLORATIVA DE INTERVENCIONES URBANAS REALIZADAS EN CONDICIONES SIMILARES A LAS DIAGNOSTICADAS}

Tras identificar las oportunidades y problemáticas existentes en el área de intervención, la investigación pasa al capítulo 3, espacio para la referenciar las intervenciones urbanas formuladas bajo el contexto de margen y que contengan similitudes con las condiciones diagnosticadas en el territorio de intervención.

Figura 5. Etapas de la Investigación Capítulo 3

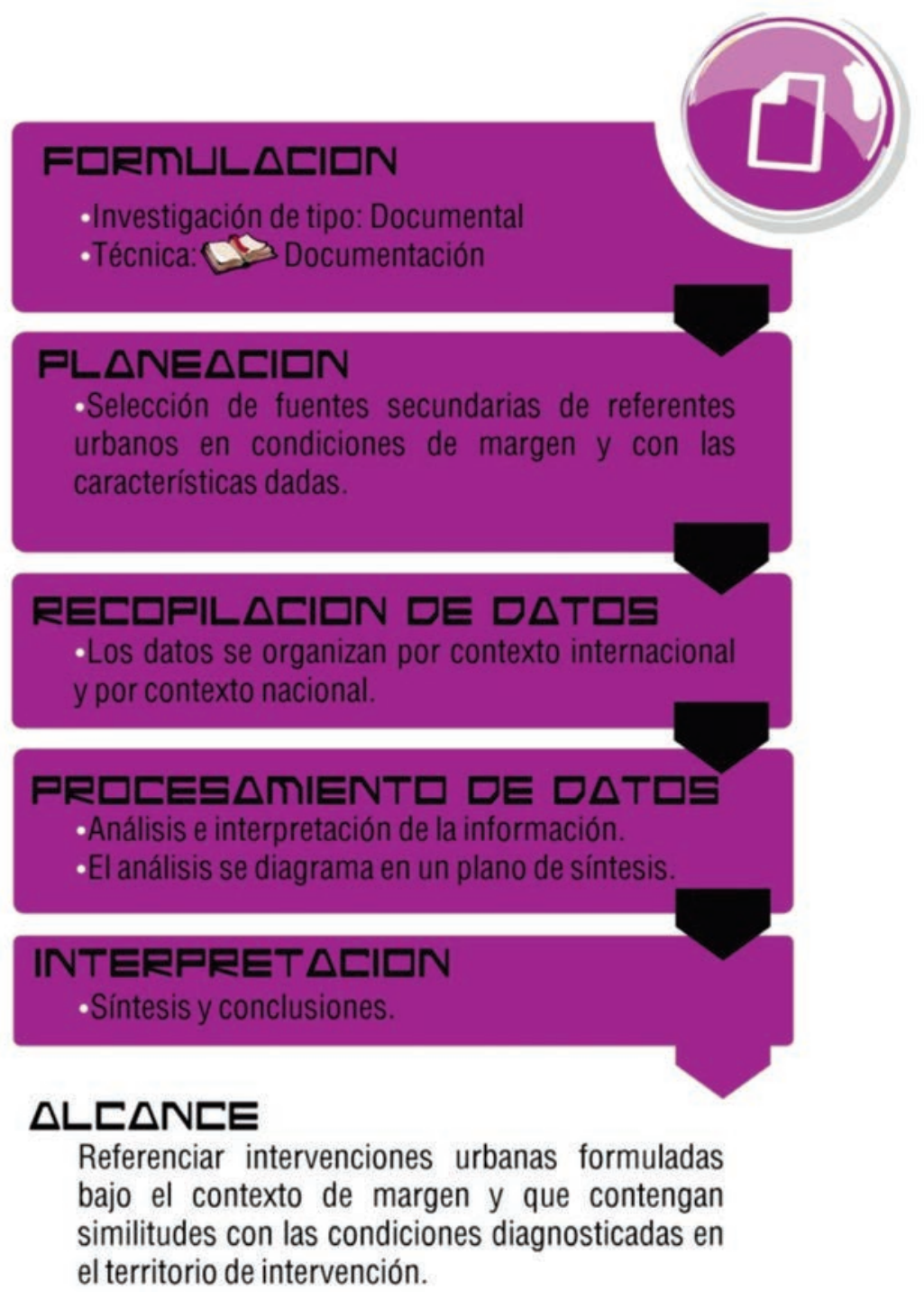

Fuente: Autoras del Proyecto 
El análisis de referentes se plantea como la posibilidad de entender cómo se enfrenta el problema y cómo se formulan soluciones en escenarios con condiciones similares, las etapas planteadas para el capítulo 3 se explican en la Imagen No. I I. Como primera instancia se inicia la documentación explorativa de intervenciones urbanas realizadas en el contexto internacional bajo las condiciones dadas, posteriormente se estudia el ámbito nacional con la intención de referenciar intervenciones bajo un contexto económico, político, social e histórico similar. El análisis de referentes se plantea como la posibilidad de entender cómo se enfrenta el problema y cómo se formulan soluciones en escenarios con condiciones similares.

Para el contexto internacional se citan dos referentes de gran importancia para la formulación de los lineamientos, el Anillo Verde de Victoria como proyecto de tratamiento ambiental y Elche Parque Industrial como proyecto de actividades similares a las diagnosticadas.

El Anillo Verde de Victoria es el resultado de un ambicioso plan de restauración y recuperación ambiental de la periferia de la cuidad que persigue fundamentalmente recuperar el valor ecológico y social del espacio a través de la creación de un continuo natural alrededor de la ciudad articulado por diversos enclaves de alto valor ecológico y paisajístico. Tiene como objetivo, promover la conservación y restauración de los enclaves naturales periurbanos para crear un continuo natural en torno a la ciudad. Integrar los parques periurbanos en la trama urbana conectándolos al mismo tiempo con el entorno natural para mejorar la accesibilidad física y ecológica entre las zonas verdes. Aprovechar la recuperación y acondicionamiento de los nuevos espacios para promover la sensibilización y educación ambiental.

Elche Parque Industrial se encuentra en el Arco Mediterráneo de España uno de los principales ejes de desarrollo a nivel autonómico nacional e internacional. Se ha consolidado como un enclave estratégico de localización empresarial, dotado de importantes infraestructura y equipamientos, con una excelente accesibilidad. Tiene como estrategias, poner en el mercado precios asequibles suelo público estratégicamente situado y dotado de infraestructuras, un configuración urbanística basada en un sistema de bulevares que articulan una trama ortogonal de vías y de circulaciones acompañadas de zonas verdes, la oferta de suelos muy flexibles: parcelas para naves aisladas, para edificaciones de naves adosadas y moni polígonos. El diseño Urbanístico del parque, la estructura viaria interna la gran proporción de espacios abiertos, dotaciones y zonas verdes, la gran imagen de conjunto, la señalización, servicios comunes, hacen de Elche, Parque Industrial un espacio empresarial de alta calidad que responden a la demanda de mejora de las condiciones urbanísticas. Su configuración urbanística destaca por un sistema de bulevares que articulan una trama de vías ortogonales de circulación de gran amplitud que rompen con la idea tradicional de polígono industrial, y que ofrecen una perfecta accesibilidad a las empresas. Las zonas verdes y la abundancia de aparcamientos públicos adquieren gran protagonismo.

En el contexto nacional se analizan dos proyectos de importante influencia en el país, El corredor ecológico de los Cerros Orientales de Bogotá y Celta Trade Park.

El componente estratégico del plan director del Corredor, Ecológico y Recreativo de los Cerros Orientales es prioritariamente ecológico: ya que recupera la estructura y función del ecosistema nativo de los cerros que antes de la conquista primó en esta cadena montañosa que limita a Bogotá por el oriente, se inicia con la restauración de las quebradas y los corredores de ladera. El principal énfasis en particular en el componente agua es generar conciencia y cultura ambiental alrededor de la misma. ¿Por qué un Corredor? Porque es una figura que ayuda a delimitar físicamente el crecimiento urbano del borde oriental de 
la ciudad, que, mediante su apropiación busca generar una veeduría pública. Por medio de la conectividad del Corredor se busca garantizar la preservación, de aproximadamente 4 I 5 ha en el borde urbano plano de organización espacial. Sus objetivos y estrategias buscan promover los valores ambientales, simbólicos, patrimoniales y paisajísticos de los Cerros Orientales; garantizar la preservación de la Reserva Forestal y el ordenamiento del borde oriental de la ciudad; recuperar la biodiversidad de los ecosistemas alterados mediante procesos de conservación, restauración y uso sostenible, generar procesos de promoción del desarrollo social, seguridad y convivencia vinculados con la creación del Corredor; aumentar el indicador de áreas públicas y de conectividad biológica de la ciudad y controlar el desarrollo de infraestructuras en el borde de la reserva forestal.

Celta Trade Park está contemplado en el PBOT del municipio de Funza, como una acción territorial estratégica desarrollada mediante el concepto de Macro proyecto para desarrollar las políticas de ordenamiento y consolidar la vocación de Polo Regional del Municipio. Ofrece al sector empresarial nacional e internacional un entorno Urbanístico de óptima calidad que le permita realizar sus operaciones de producción, abastecimiento y distribución con altos niveles de innovación, productividad y competitividad. El proyecto se concibe como una plataforma logística empresarial diseñada con una concepción moderna para responder a los nuevos retos que impone la competencia global y que en el caso colombiano son aún mayores por cuanto sus grandes centros de producción y consumo se encuentran alejados de las costas.

\section{CAPÍTULO 4. LINEAMIENTOS ESTRATÉGICOS PARA EL CRECIMIENTO SOSTENIBLE DEL MARGEN OCCIDENTAL DE BUCARAMANGA}

Los lineamientos estratégicos para el crecimiento sostenible del margen occidental se formulan como un tratamiento eco urbanístico de este territorio periurbano, busca desarrollar acciones de recuperación a los ecosistemas afectados y potencializar las actividades económicas presentes a fin de estructurar el desarrollo sostenible de esta extensión de territorio. La interfaz periurbana generalmente se caracteriza por la convergencia de jurisdicciones municipales, en nuestro caso Bucaramanga y Girón, haciendo necesaria la articulación permanente de los entes de gestión de cada municipio y la formulación de políticas que organicen y estructuren el desarrollo sostenible del territorio ocupado por los municipios que conforman el Área Metropolitana.

Completos los procesos de investigación histórica sobre el crecimiento de la ciudad de Bucaramanga, la investigación descriptiva del reconocimiento de los márgenes urbanos, la investigación diagnóstica del margen seleccionado y el análisis de los referentes relacionados a las temáticas abordadas, la investigación pasa a su fase propositiva, en la cual se formulan unos lineamientos estratégicos que sirvan de guía para el desarrollo sostenible del margen Occidental. Para el desarrollo metodológico del capítulo se plantean 3 fases de formulación, la fase I busca establecer el estructurante teórico principal planteando el rol futuro, el rol futuro permite la formulación de la visión prospectiva hipotética del desarrollo del territorio una vez intervenido, la prospectiva es una herramienta metodológica que facilita la reflexión colectiva sobre el territorio y la construcción de imágenes o escenarios futuros. Tras formular el rol futuro e identificar que se quiere potencializar y regenerar del territorio, la fase 2 formula los lineamientos estratégicos para el desarrollo sostenible del territorio, para el desarrollo de esta fase se entenderá como lineamiento al conjunto de acciones específicas que determinan el orden, la disposición y la organización de los componentes físicos y sociales del entorno. 
La fase 3 estructura físicamente los componentes fundamentales para el ordenamiento del territorio: Componente Ambiental, Actividades y de Movilidad

Figura 6. Fases de Formulación Capítulo 4

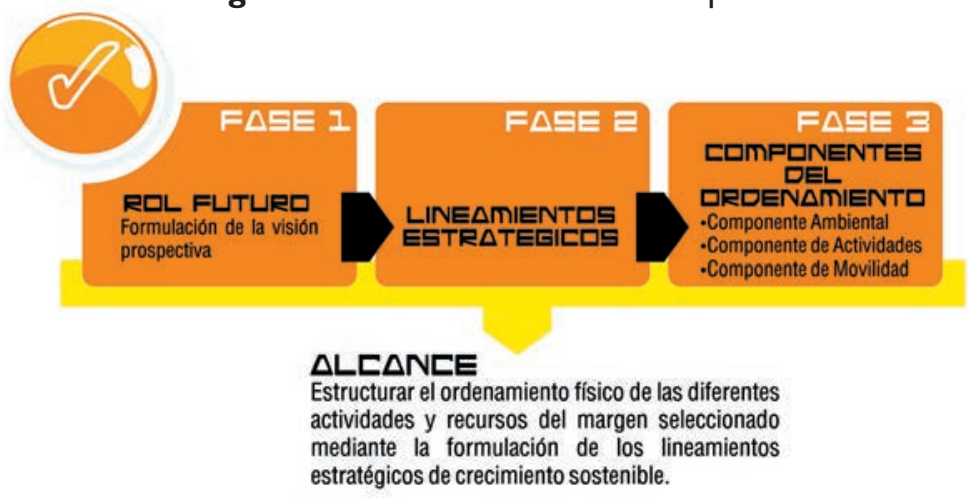

Fuente: Autoras del Proyecto

\section{FORMULACIÓN DEL ROL FUTURO PARA GENERAR UNA VISIÓN PROSPECTIVA HIPOTÉTICA DEL DESARROLLO DEL TERRITORIO UNA VEZ INTERVENIDO}

Área funcional articulada al modelo territorial urbano estructurada por el "Corredor Ecológico de la ronda del Río de Oro" delimitante físico del crecimiento urbano y escenario de diversos elementos de espacio público enfocados en la recuperación, educación y cuidado del Medio Ambiente y la Naturaleza. Territorio de vocación Industrial, Agroindustrial y Comercial organizado bajo el concepto de "Parque Industrial y Agroindustrial Urbano donde el protagonista es el ciudadano que recorre, disfruta e interactúa con las oportunidades brindadas por la actividad del sector de forma cómoda y autónoma.

\section{LINEAMIENTO ESTRATÉGICO AMBIENTAL, CORREDOR ECOLÓGICO DE LA RONDA DEL RÍO DE ORO}

\section{Objetivo general}

Recuperar el Valor Ecológico y Social del Río de Oro mediante un corredor que delimite el crecimiento del la ciudad y articule escenarios de espacio Público a lo largo de la ronda del río para permitir el encuentro de la comunidad y aportar un espacio natural a la agitada vida urbana así como inculcar interés en el cuidado del medio ambiente que forme ciudadanos responsables capaces de vivir en armonía con la naturaleza.

\section{Objetivos específicos}

- Rescatar la importancia ecológica del Valle del Río de Oro mediante escenarios urbanos que inciten a los ciudadanos a disfrutar y valorar el paisaje.

- Entregar a la comunidad un espacio digno y confortable para la recreación y el sano esparcimiento.

- Formular acciones para el tratamiento en la fuente de aguas residuales e industriales que permitan recuperar las quebradas y ríos que depositan aguas contaminadas en el Río de Oro. 
- Proponer espacios que permitan enseñar a la comunidad la importancia de transformar los desechos en recursos y a administrar adecuadamente los elementos naturales disponibles en la ciudad.

- Formular senderos ecológicos que permitan el contacto directo con la naturaleza y el desarrollo de recorridos didácticos informativos sobre temáticas como reciclaje, uso racional de los recursos y técnicas de reforestación entre otros.

Plano I. Componente Ambiental, Corredor ecológico de la ronda del Río de Oro

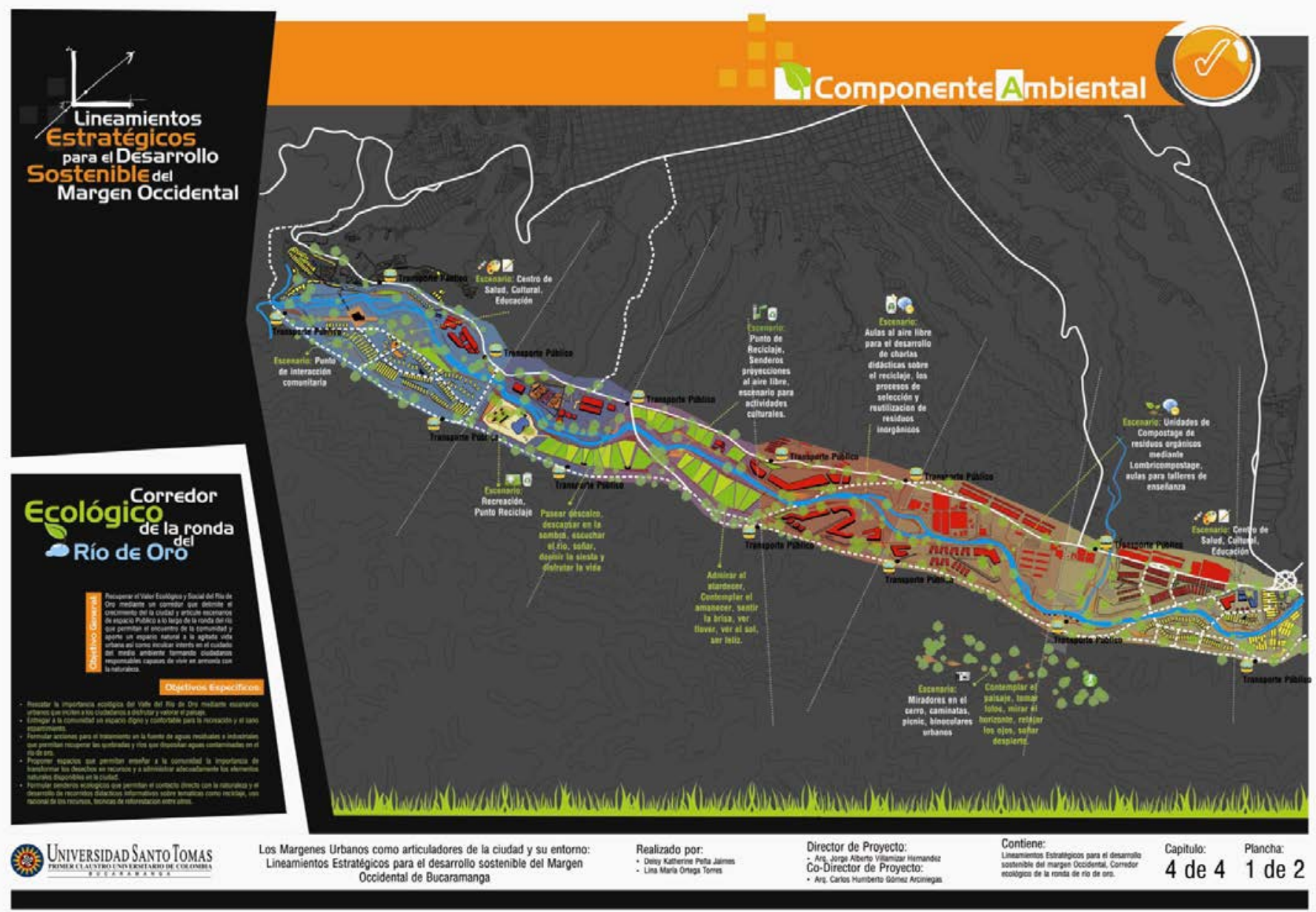

Fuente: Autoras del Proyecto

\section{LINEAMIENTO ESTRATÉGICO DE ACTIVIDADES, ECOPARQUE INDUSTRIAL Y AGROINDUSTRIAL Objetivo general}

Formular un entorno urbanístico que permita solucionar las necesidades de infraestructura y logística así como organizar las actividades industriales, agroindustriales y de distribución viables en el contexto económico del Área Metropolitana de Bucaramanga con servicios dotacionales, espacio público, zonas verdes y áreas comunes que aporten calidad de vida a la comunidad. 


\section{Objetivos específicos}

- Potencializar el sector como un motor de la economía local y regional aprovechado su ubicación geoestratégica que permite una optima conexión con la Costa Atlántica, Barrancabermeja, Medellín, Cúcuta, Venezuela y el Centro del País, para la distribución y comercialización de productos y servicios.

- Reubicar a las empresas que generan fuertes impactos en el casco urbano para aportar nuevas áreas para la formulación de planes de renovación urbana que generen vivienda digna con todas las oportunidades y comodidades que brinda la vida urbana

- Aportar un escenario urbano que permita desarrollar sosteniblemente la actividad industrial y empresarial en total compromiso con el tratamiento de desechos y su reutilización en los ciclos productivos así como el uso racional de los recursos naturales y el cuidado al entorno natural.

Plano I. Componente Ambiental, Corredor ecológico de la ronda del Río de Oro

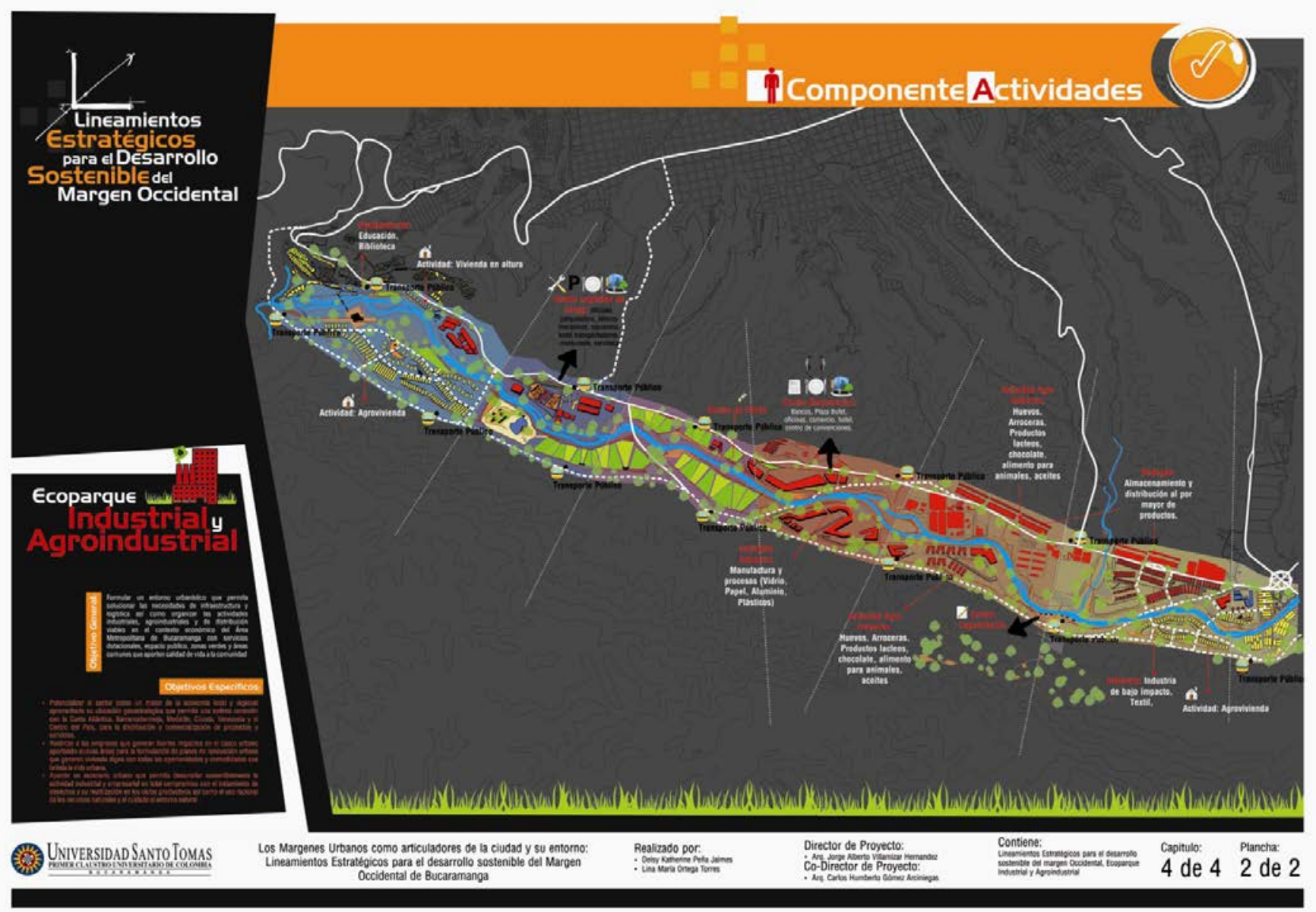




\section{BIBLIOGRAFÍA}

ACCIONES CON MI BARRIO, MEDELLÍN HACIA UN URBANISMO SOCIAL. Alcaldía de Medellín, Empresa de Desarrollo Urbano. Medellín, 2004

ANDER-EGG, Ezequiel. Métodos y técnicas de investigación social. Lumen, Humanitas, 2004

BUNGE, Mario. La investigación científica: su estrategia y su filosofía. Barcelona, Siglo XXI, 1989

CASTELLS, Manuel. Imperialismo y América Latina. Barcelona, Gustavo Gili, 1973

La Cuestión Urbana. México, Siglo XXI Editores, 1978

CEBALLOS RAMOS, Olga Lucía. Vivienda social en Colombia, Una mirada desde su legislación 1918-2005. Bogotá, Pontificia Universidad Javeriana. 2008

DECRETO 469 DE 2003, Ajustes al Plan de Ordenamiento Territorial. Alcaldía Mayor de Bogotá D.C. 2003

ENTRENA DURÁN, Francisco. Procesos de Peri urbanización y cambios en los modelos de ciudad. Un estudio europeo de casos sobre sus causas y consecuencias. Papers 78. Universidad de Granada, Departamento de Sociología, España, 2005

FERIA TORIBIO, José María. Nuevas periferias urbanas y planificación pública. En DOMÍNGUEZ, R. (coord.): La ciudad. Tamaño y crecimiento, pp. 309-3 I7. Málaga, Departamento de Geografía de la Universidad de Málaga y AGE, 1999

FRANCO, Ángela María. Desarrollos prácticos en Ordenamiento Territorial, La experiencia de Tuluá. Colección Estudios del Territorio. Bogotá, Escala S.A, 2007

GIMÉNEZ BALDRÉS, Enrique J. Parcelaciones Residenciales Subnormales. Valencia, Universidad Politécnica de Valencia, 2010

GÓMEZ ARCINIEGAS, Carlos Humberto. Agricultura Periurbana: nuevos roles de la agricultura de proximidad en la planificación de las periferias urbanas. Revista M, Volumen 6 No 2, Julio-Diciembre 2009. Bucaramanga, Universidad Santo Tomas, Facultad de Arquitectura, 2009

GUZMÁN, Inés Ángela; PERGOLIS, Juan Carlos; AYALA, Leonardo. Ciudad Colombiana, Asuntos Urbanos. Revista del Departamento de Urbanística. Facultad de Artes, Universidad Nacional. 2002

INGERSOLL, Richard. Sprawltown. Roma, Meltemi editore, 2004

LEFEVRE, Henry. El derecho a la ciudad historia, ciencia y sociedad. Barcelona, Ediciones península, 1978

LEÓN GUARÍN, Libardo. Bucaramanga en vísperas de 2 Siglos. Bucaramanga, 1980 
M. C TREU, D. Palazzo. Margini. Descrizioni, strategie. Italia, progetti, 2006

MENDOZA MORALES, Alberto. Colombia: Ordenamiento Territorial. Revista Geografía. Bogotá, Sociedad Geográfica de Colombia.

MIKEL, Razkin Fraile. De la potencialidad a la realidad en la franja periurbana del norte de Pamplona-Iruñea. Disponible en Internet en EUSKOSHOP, euskonews\&media http://www. euskonews.com/018Izbk/gaial8102es.html

NAREDO, José Manuel. Sobre el origen, el uso y el contenido del término sostenible. Ci [ur] Cuadernos de investigación urbanística, Departamento de Urbanística y ordenación del territorio, Escuela Técnica Superior de Arquitectura, Universidad Politécnica de Madrid, Madrid, España, 2004

PALAZZO, Danilo. Responsabilità progettuali e paesaggio dei margine urbani. en Ri-viste per la progettazione del paesaggio, año 4, No. 6, UNIFI, Florencia, 2006

Plan de Ordenamiento Territorial, Alcaldía de Bucaramanga. Formulación, Componente Rural y Componente Urbano.

RUEDA Gómez, Néstor José. Paradojas de un Ordenamiento Urbano. Bucaramanga, Universidad Santo Tomas, 2003

SABINO, Carlos. El proceso de Investigación. Bogotá, Editorial Panamericana, 1992 
SARASA, José Andrés. Las Áreas periurbanas: Espacios plurifuncionales en crisis. IX Coloquio de Geógrafos Españoles. Murcia, Centro Editorial de Servicios y Publicaciones Universitarias, 1985

TORO VASCO, Carolina; VELASCO BERNAL, Vanessa; NIÑO SOTO, Alexánder. El borde como espacio articulador de la Ciudad Actual y su Entorno. Revista de Ingenierías Universidad de Medellín, Julio-Diciembre, Año/Vol 4, No. 007. Universidad de Medellín, Colombia, 2005

UTRIA GROSSER, Rubén Darío. Metropolización de la Sabana de Bogotá. Revista Geografía, Vol. 43, No. 127. Bogotá, Sociedad Geográfica de Colombia, 1998.

\section{PÁGINAS WEB CONSULTADAS}

Anillo de Vitoria, Página Web Oficial. http://www.vitoria-gasteiz.org/anilloWeb/es/html/ index.shtml

Celta Trade Park, Página Web Oficial. http://www.celtatradepark.com/

Corredor de los Cerros Orientales de Bogotá, Página Web Oficial. http://www.cerrosdebogota.org/

Elche Parque Industrial, Página Web Oficial http://www.elcheparqueindustrial.com 